\title{
Structural characterization of terrestrial microbial Mn oxides from Pinal Creek, AZ
}

\author{
John R. Bargar ${ }^{\mathrm{a}, *}$, Christopher C. Fuller ${ }^{\mathrm{b}}$, Matthew A. Marcus ${ }^{\mathrm{c}}$, Adrian J. Brearley ${ }^{\mathrm{d}}$, \\ M. Perez De la Rosa ${ }^{a}$, Samuel M. Webb ${ }^{\text {a }}$, Wendel A. Caldwell ${ }^{\mathrm{c}}$ \\ a Stanford Synchrotron Radiation Lightsource, 2575 Sand Hill Road, Building 137, MS 69, Menlo Park, CA 94025, USA \\ ${ }^{\mathrm{b}}$ US Geological Survey, Water Resources Division, 345 Middlefield Road, MS 465, Menlo Park, CA 94025, USA \\ ${ }^{c}$ Advanced Light Source, Lawrence Berkeley National Laboratory, One Cyclotron Road, Berkeley, CA 94720, USA \\ ${ }^{\mathrm{d}}$ Department of Earth and Planetary Sciences, MSC03-2040, University of New Mexico, Albuquerque, NM 87131, USA
}

Received 19 March 2008; accepted in revised form 15 October 2008; available online 25 November 2008

\begin{abstract}
The microbial catalysis of $\mathrm{Mn}(\mathrm{II})$ oxidation is believed to be a dominant source of abundant sorption- and redox-active Mn oxides in marine, freshwater, and subsurface aquatic environments. In spite of their importance, environmental oxides of known biogenic origin have generally not been characterized in detail from a structural perspective. Hyporheic zone Mn oxide grain coatings at Pinal Creek, Arizona, a metals-contaminated stream, have been identified as being dominantly microbial in origin and are well studied from bulk chemistry and contaminant hydrology perspectives. This site thus presents an excellent opportunity to study the structures of terrestrial microbial Mn oxides in detail. XRD and EXAFS measurements performed in this study indicate that the hydrated Pinal Creek Mn oxide grain coatings are layer-type Mn oxides with dominantly hexagonal or pseudo-hexagonal layer symmetry. XRD and TEM measurements suggest the oxides to be nanoparticulate plates with average dimensions on the order of $11 \mathrm{~nm}$ thick $\times 35 \mathrm{~nm}$ diameter, but with individual particles exhibiting thickness as small as a single layer and sheets as wide as $500 \mathrm{~nm}$. The hydrated oxides exhibit a 10- $\AA$ basal-plane spacing and turbostratic disorder. EXAFS analyses suggest the oxides contain layer $\mathrm{Mn}(\mathrm{IV})$ site vacancy defects, and layer Mn(III) is inferred to be present, as deduced from Jahn-Teller distortion of the local structure. The physical geometry and structural details of the coatings suggest formation within microbial biofilms. The biogenic Mn oxides are stable with respect to transformation into thermodynamically more stable phases over a time scale of at least 5 months. The nanoparticulate layered structural motif, also observed in pure culture laboratory studies, appears to be characteristic of biogenic Mn oxides and may explain the common occurrence of this mineral habit in soils and sediments.
\end{abstract}

\section{INTRODUCTION}

Manganese oxides, reactive high surface area particles, play innumerable roles in the transformation and cycling of major and trace elements in freshwater and marine environments (Murray, 1975; O'Reilly and Hochella, 2003; Tebo et al., 2004; Villalobos et al., 2005b; Webb et al., $2005 \mathrm{~b}, \mathrm{c})$. Mn oxides are among the strongest of naturally

\footnotetext{
* Corresponding author. Fax: +1 6509264100 .

E-mail address: bargar@slac.stanford.edu (J.R. Bargar).
}

occurring metal sorbents and oxidatively degrade or transform numerous organic and inorganic compounds, including humic and fulvic acids, aromatic hydrocarbons, $\mathrm{Cr}$ (III), Co(II), and hydrogen sulfide (Jenne, 1967; Huang, 1991). Oxidation of $\mathrm{Mn}(\mathrm{II})$ in surface and near-surface environments is believed to be dominantly mediated by microbes (Tebo et al., 2004). This belief is based primarily upon the ubiquity of $\mathrm{Mn}(\mathrm{II})$-oxidizing microorganisms in the environment (Tebo et al., 2004) and upon the much faster rates of $\mathrm{Mn}(\mathrm{II})$ oxidation at circum-neutral $\mathrm{pH}$ when catalyzed by microorganisms as compared to rates of homogeneous or surface-mediated abiotic mechanisms (Morgan, 2005). 
It has been suggested that biogenic Mn oxides dominate the pool of reactive $\mathrm{Mn}$ oxides in the environment. However, laboratory-produced bacteriogenic $\mathrm{Mn}$ oxides are reactive and may transform into abiotic secondary $\mathrm{Mn}$ oxides in the presence of the common solutes (e.g., Bargar et al., 2005; Webb et al., 2005a). The assertion that "primary" biogenic Mn oxides dominate Mn oxide chemistry in aquatic environments thus remains open to testing. A more informed understanding of these important natural materials is required and must rest upon observations at field sites where biogenic $\mathrm{Mn}$ (II) oxidation has been clearly established as the dominant process. Remarkably few such studies have been performed (Lind and Hem, 1993; Best et al., 1999; Bilinski et al., 2002).

We report here detailed structural characterizations of terrestrial microbial $\mathrm{Mn}$ oxides obtained from the hyporheic zone in the perennial reach of Pinal Creek, AZ. Pinal Creek is a low-gradient, sand and gravel bed stream, originating in the Pinal Mountains, south of Globe, Arizona, that has been impacted by $\mathrm{Cu}$ mining activities in the Pinal Creek watershed. Extensive Mn oxide coatings $(<1$ to $\mathrm{ca}$ $35 \mu \mathrm{m}$ thick) have developed over streambed sediments in the perennial reach of the stream following discharge of $\mathrm{Mn}$ (II)-bearing ground water to the creek. At least three studies have investigated the processes responsible for $\mathrm{Mn}$ oxide formation in the hyporheic zone of Pinal Creek. Harvey and Fuller (1998) studied Mn(II) oxidation by hyporheic zone sediments in batch experiments using natural and artificial stream water $\left(\mathrm{pH} 7, \sim 0.7 \mathrm{mM} \mathrm{Mn}^{2+}\right.$ ) in the presence and absence of microbial poisons $\left(\mathrm{NaN}_{3}\right.$, tetracycline, and penicillin). They found that $\mathrm{Mn}$ (II) oxidation was strongly enhanced in the presence of microbial activity. They subsequently proposed that microbial Mn oxidation coupled with hydrologic exchange of stream water with the streambed (hyporheic zone) dominates the downstream attenuation of dissolved Mn. Subsequently, Marble et al. (1999) conducted batch incubations of streambed sediments in artificial stream water with and without the microbial poison $\mathrm{NaN}_{3}$ at various $\mathrm{Mn}(\mathrm{II})$ concentrations (0.2$1.5 \mathrm{mM}), \mathrm{O}_{2}$ concentrations, and $\mathrm{pH}$ values (6-7.8). They reported significantly faster $\mathrm{Mn}(\mathrm{II})$ oxidation in unpoisoned sediments, from which they concluded that the hyporheic zone $\mathrm{Mn}$ oxide grain coatings were primarily of biotic origin. Robbins and Corley (2005) investigated Mn oxidation using glass slides emplaced above and in the sediment bed in Pinal Creek. They noted that biofilms commonly formed on their samples within 30 days of exposure. Above the sediment bed, most of the Mn oxidation was described as being associated with Ulothrix sp. (green alga) and holdfasts of Leptothrix discophora, a known Mn-oxidizing bacterium (Tebo et al., 2004). At the transition zone in shallow sediments, they noted that $\mathrm{Mn}$ oxidation was associated most with holdfasts of $L$. discophora, "brown rod" microbes, and thinly coated bacterial filaments. These observations establish microbial Mn(II) oxidation as the dominant source of the hyporheic zone coatings and suggest that biofilms were important formation environments for biogenic Mn oxides.

Recent investigations have provided significant new information regarding the structures of bacteriogenic $\mathrm{Mn}$ oxides produced in pure cultures in the laboratory. X-ray diffraction and EXAFS spectroscopy measurements of bacteriogenic $\mathrm{Mn}$ oxides produced by the common soil and freshwater bacterium, Pseudomonas putida, MnB1, show these materials to be a poorly-crystalline birnessite-like layered Mn oxide having hexagonal symmetry and containing only edge-sharing $\mathrm{Mn}^{4+} \mathrm{O}_{6}$ octahedra, with one-sixth of the cation $\left(\mathrm{Mn}^{4+}\right)$ sites vacant (Villalobos et al., 2003, 2006). Similarly, Mn biooxides produced by the marine bacterium, Bacillus sp., strain SG-1, were found to be layered Mn oxides possessing hexagonal layer symmetry with abundant layer Mn(IV) site vacancies (Bargar et al., 2005; Webb et al., 2005b,c). It was posited that protons, $\mathrm{Mn}^{3+}$, and $\mathrm{Mn}^{2+}$ bonded to the sheets above or below these vacancy sites, along with solvated interlayer cations, help to balance charge. The basic layer structure with $\mathrm{Mn}^{3+}$ bonded above vacancies is depicted in Fig. 1. Consistent with these conclusions, bacteriogenic Mn oxides produced by L. discophora SP-6 have been reported to be composed of single birnessite layers (Jurgensen et al., 2004). The lack of (001) X-ray diffraction maxima in SG-1 Mn biooxides was attributed to a lack of stacking of the particles along the $c$ direction (i.e., perpendicular to the layers), and/or to long-range disorder within the sheets. It can thus be concluded that this nanoparticulate layered structural motif is characteristic of (but not necessarily unique to) laboratory biogenic Mn oxides. These conclusions lead one to question if environmental biogenic Mn oxides exhibit such characteristics (intriguingly, such features are frequently reported for poorly crystalline natural Mn oxides of possible biogenic origin (Post, 1999; Manceau et al., 2005; Bodei et al., 2007)). Establishing similarity between laboratory and environmental biogenic $\mathrm{Mn}$ oxides, were it to occur, would represent a significant step forward because it would provide the scientific basis to
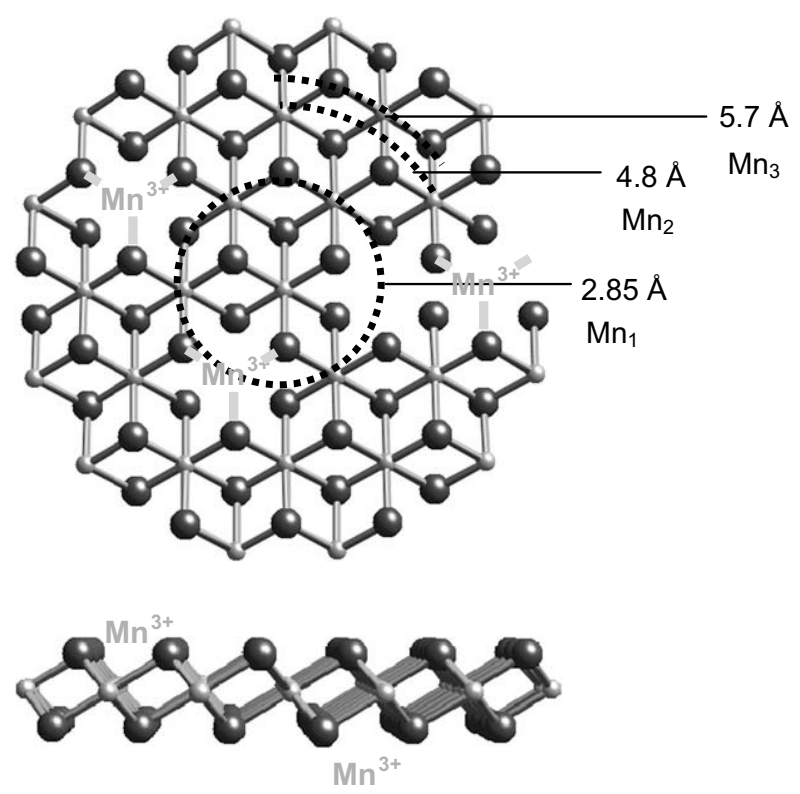

Fig. 1. Ball-and-stick representation of biogenic hexagonal birnessite structure with $15 \% \mathrm{Mn}$ layer site vacancies. $\mathrm{Mn}^{3+}$ ions (grey) are indicated above and below layer Mn(IV) site vacancies. 
model the behavior of environmental Mn oxides based on data from laboratory studies.

Following reaction with solutes such as $\mathrm{Mn}^{2+}$ or $\mathrm{Ca}^{2+}$, SG-1 biooxides showed increased stacking and in-plane layer ordering (Bargar et al., 2005; Webb et al., 2005b,c), indicating that these solutes were reacting with the biooxides to produce more crystalline products. It can thus be concluded that, in sea water, SG-1 biooxides exhibited a strong affinity for $\mathrm{Ca}^{2+}$ as the interlayer cation, in spite of the fact that $\mathrm{Mg}^{2+}$ is present at higher concentration. Interestingly, the concentration of $\mathrm{Ca}^{2+}$ in Pinal Creek ground water, $c a 10 \mathrm{mM}$, is the same as in sea water. The association of $\mathrm{Ca}$ with $\mathrm{Mn}$ in Pinal Creek biooxides, if found to occur, would be consistent with a biogenic origin.

We have used bulk and microfocused synchrotron-based X-ray diffraction (SR-XRD) and Extended X-ray Absorption Fine Structure (EXAFS) spectroscopy coupled with electron microscopy to address the mineralogy of Pinal Creek hyporheic zone grain coatings. Microprobe measurements allow spatial separation of the grain coatings from the much more abundant host grains that would otherwise interfere with analysis. Bulk measurements (millimeter-size beam spot), which were performed on grain coatings that had been mechanically abraded off of mineral grains (removes about $20 \%$ of the total sediment Mn content), average over all species and environments present in the samples. The two spatial length scales thus provide complementary views of the chemical and physical make-up of the Mn oxide coatings.

\subsection{Background}

\subsubsection{Pinal Creek site description}

Relevant aspects of the geology, geochemistry, and hydrology of Pinal Creek (Brown and Eyechaner, 1996; Brown et al., 1999) are briefly summarized here. The 5- to 7-km perennial reach of Pinal Creek relevant to this study is a sand- and gravel-bed stream with an average slope of $1 \%$, an average width of $2.3 \mathrm{~m}$, and an average depth of $15 \mathrm{~cm}$. Pools are almost nonexistent and riffles or cascades are fairly unusual (Harvey and Fuller, 1998). Perennial flow begins about 5- to $7 \mathrm{~km}$ upstream of Inspiration Dam (Fig. EA-1) and results from constriction of an alluvial aquifer by underlying bedrock in the Pinal Creek basin. Copper mining operations have generated acidic ground water ( $\mathrm{pH}<4,18 \mathrm{mM} \mathrm{Fe}, 1.5 \mathrm{mM} \mathrm{Cu}$ ) in the alluvial aquifer upgradient of the perennial reach that has formed a plume of partially neutralized $(\mathrm{pH} 5-6.5)$, contaminated ground water with elevated dissolved $\mathrm{Mn}, \mathrm{Co}, \mathrm{Ni}$, and $\mathrm{Zn}$ (up to $1.5 \mathrm{mM}, 20 \mu \mathrm{M}, 25 \mu \mathrm{M}$, and $25 \mu \mathrm{M}$, respectively (Stollenwerk, 1994)). Water chemistry of the perennial reach of Pinal Creek is dominated by discharge of this neutralized, contaminated ground water, which occurs over the upper $2-3 \mathrm{~km}$ of perennial flow and contributes about $50 \%$ of the base-flow discharge (Eychaner, 1991) at the exit of the alluvial basin. Stream-water chemistry is characterized by high dissolved solids (e.g., 11-14 $\mathrm{mM} \mathrm{SO}_{4}{ }^{-2}$ and $8-$ $12 \mathrm{mM} \mathrm{Ca}^{2+}$ ) and elevated dissolved $\mathrm{Mn}, \mathrm{Co}, \mathrm{Ni}, \mathrm{Cu}$, and $\mathrm{Zn}$. Stream water $\mathrm{pH}$ increases from about 6 near the head of perennial flow to about 7.8 at Inspiration Dam due to $\mathrm{CO}_{2}$ outgassing (Choi et al., 1998). Dissolved Mn concentrations in stream and shallow ground water increased from background levels in 1984 to levels approaching $1.3 \mathrm{mM}$ by 1990 with little subsequent change through 1999 (Brown et al., 1996). Hyporheic exchange of stream water into the streambed coupled with ongoing microbial $\mathrm{Mn}(\mathrm{II})$ oxidation was proposed to result in the observed attenuation of $20 \%$ of the Mn load and up to $70 \%$ of the $\mathrm{Co}, \mathrm{Ni}$ and $\mathrm{Zn}$ contaminant loads over $5 \mathrm{~km}$ of stream flow (Fuller and Harvey, 2000). At the time of sampling (1997 and 1998), crusts of Mn-oxide cemented sediments covered the streambed in some reaches of the stream.

Interception and remediation of the acidic ground water plume began in 1999 with the installation of an impermeable barrier with extraction wells, and a lime treatment plant upgradient of the perennial stream reach with discharge of treated water to the ephemeral stream channel at a flow rate equal to historic base flow at the basin outlet. The remediation effort has contributed to decreases in dissolved Mn concentrations at the basin outflow to less than $5 \%$ of the pre-remediation levels (Table EA-1).

\subsubsection{Pinal Creek sediment mineralogy}

Cemented Mn oxide crusts and noncemented Mn oxidecoated grains have been studied previously using bulk XRD and electron microscopy. Major minerals identified in crusts and streambed sediments include quartz, feldspar, and magnetite (Lind and Hem, 1993; Best et al., 1999; Bilinski et al., 2002). Trace minerals include mica and chlorite (non-magnetic fraction), ilmenite, and hematite (magnetic fraction). Bilinski et al. (2002) studied the mineralogic composition of black cemented streambed Mn oxide crusts that were in direct contact with stream flow at Inspiration dam and Setka Ranch (Fig. EA-1). They observed a Mn oxide mineral having a $10.1-\AA$ peak resembling buserite (a layered Mn oxide) that could not be attributed to mica (intense 4.49 and $3.66 \AA$ mica peaks were not present, and further, the 10.1- $\AA$ peak disappeared following $2 \mathrm{M} \mathrm{HCl}$ digestion). The $10.1 \AA$ peak was found to persist after dehydration at $110^{\circ} \mathrm{C}$, leading to the conclusion that it is a tunnel-structured material (as opposed to a layered Mn oxide). A 7.5$\AA$ peak was observed and attributed to the $\mathrm{Ca}$ birnessites, rancieite $\left((\mathrm{Ca}, \mathrm{Mn}(\mathrm{II})) \mathrm{Mn}(\mathrm{IV})_{4} \mathrm{O}_{9} \cdot 3 \mathrm{H}_{2} \mathrm{O}, \mathrm{Ca}>\mathrm{Mn}(\mathrm{II})\right)$ or takanelite $(\mathrm{Mn}(\mathrm{II})>\mathrm{Ca})$. A minor peak at 7.15-7.20 was attributed to a birnessite phase, which was postulated to be a dehydration product of buserite. Best et al. (1999) reported that uncemented $\mathrm{Mn}$ oxide grains from the $\mathrm{R} 2 \mathrm{~B}$ site samples collected at the same location and time as those discussed in this study contained the minerals birnessite, rancieite, rhodochrosite, pyrolusite, and cryptomelane (in approximate decreasing order of relative concentration). These authors noted that Pinal Creek stream water at the R2B location plots across several Mn mineral stability fields, including birnessite, and pyrolusite. Lind and Hem (1993) reported that the $<63 \mu \mathrm{m}$ size fraction from recently formed crusts collected near Inspiration Dam contained a mixture of rancieite and takanelite. The average Mn oxidation state in the $<75-\mu \mathrm{m}$ size fraction was found to be $3.78 \pm 0.04$. Sediments from Setka Ranch were found to contain $\mathrm{Na}$ birnessite. 


\section{MATERIALS AND METHODS}

\subsection{Sample collection and preparation}

Pinal Creek sample description, names, and analysis procedures are summarized in Table 1. Samples of streambed uncemented sediment grains from Pinal Creek were collected at sites Z9A, R2B, AK1, and SIQ (names designated at time of field experiments) $1-2 \mathrm{~km}$ downstream of the discharge of metal contaminated ground water, (Fig. EA-1) in June 1998, May 1997, and February 2000, respectively. The Z9A site corresponds to site 5 of Fuller and Harvey (2000), whereas the R2B site is located about $50 \mathrm{~m}$ upstream of site 7 and is the most downstream hyporheic flow path site described in Fuller and Harvey (2000). These sites were chosen because they were located in the reach of Pinal Creek where reactive loss of $\mathrm{Mn}$ from stream water has been previously documented. Water chemistry for overlying stream water and for shallow ground water $(1 \mathrm{~m})$ below the streambed was similar at the two sites (Table EA-2). At both sites, the streambed was comprised largely of sandsized sediments in the form of elongated bars devoid of alga and aquatic plants. The sediment likely represents recent deposition because it was not cemented by Mn oxides into impenetrable crust found at many other locations in Pinal Creek (Eychaner, 1991). At site R2B, dissolved bromide from an upstream tracer injection was detected at depths up to $17 \mathrm{~cm}$ in the streambed illustrating the exchange of surface water into the streambed at this site (Fuller and Harvey, 2000). Details of the SIQ site are provided in Section 2.1.3.

Sediments at site R2B were collected by carefully scooping from the upper $3 \mathrm{~cm}$ of streambed and by using a push corer. Sediments were collected one day after sampling for interstitial water chemistry. The $24-\mathrm{cm}$ core was sectioned in $3 \mathrm{~cm}$ intervals upon recovery. Sediment and interstitial water metals concentration profiles from this site are presented in Fuller and Harvey (2000). The upper $3 \mathrm{~cm}$ of the sediment surface at site Z9A was collected by scooping in June, 1998. Although hyporheic zone interstitial water profiles were not measured at this site, the elevated sediment metal concentrations, grain size and streambed morphology are similar to $\mathrm{R} 2 \mathrm{~B}$, indicating active hyporheic exchange and metal attenuation were likely occurring. Surface sediments were collected from the upper $10 \mathrm{~cm}$ of the creek bed at site AK1 (located about $300 \mathrm{~m}$ upstream of the Z9A site) by scooping in February 2000, 3 months after the start of treated water discharge to the stream channel above the head of perennial flow. The returned treated water had no measurable dissolved metals and accounted for $70-80 \%$ of stream flow, with the balance of flow coming from discharge of the remnant ground-water contaminant plume (containing up to $1 \mathrm{mM} \mathrm{Mn}^{2+}$ ) over a $2-\mathrm{km}$ reach upstream of site AK1. Surface sediment samples from all three sites were sieved through $1 \mathrm{~mm}$ screen in the field using ambient stream water to remove coarse grained (>1 mm) sediments (Kay et al., 2001). Surface sediment samples were stored at $4{ }^{\circ} \mathrm{C}$, with an air headspace, and maintained moist with ambient stream water until use. Core intervals and subsamples of surface samples were air dried for partial and total chemical extraction, and for preparation of thin sections. Magnetic minerals ( 7 and $15 \mathrm{wt} \%$ at Z9A and R2B, respectively) were removed from sediments by repeated passes of a magnet encased in a centrifuge tube.

Metal concentrations of streambed sediments $(<1 \mathrm{~mm})$ and abraded coatings were determined following partial chemical extraction using $0.1 \mathrm{M}$ hydroxylamine $\mathrm{HCl}$ in $0.05 \mathrm{~N} \mathrm{HNO}_{3}(\mathrm{HH})$ at room temperature for $1 \mathrm{~h}$ as previously described (Fuller and Harvey, 2000). Mn extracted by this technique is operationally defined and intended for comparison to our previous work. Drying samples via this technique is not expected to change the $\mathrm{HH}$-extractable Mn (Thomson et al., 1980). Total metal concentrations were determined following total dissolution of separate sediment samples using $\mathrm{HF}-\mathrm{HNO}_{3}$ digestion. The resulting extraction and total dissolution samples solutions were analyzed by ICP-OES (see Fuller and Harvey, 2000, for details, including replicate procedures to assess reproducibility). Bulk sediments had $\mathrm{HH}$-extracted $\mathrm{Mn}$ concentrations of 3930 and $4000 \mathrm{ppm}$ and total Mn concentrations of 4810

Table 1

Key information for Pinal Creek samples. All $\mu$-XRD/XAS/SXRF samples were mounted on Kapton film, except for R2BX11, which was mounted on a glass slide.

\begin{tabular}{|c|c|c|c|c|c|}
\hline Name & $\begin{array}{l}\text { Collection } \\
\text { site }\end{array}$ & $\begin{array}{l}\text { Depth } \\
(\mathrm{cm})^{\mathrm{a}}\end{array}$ & $\begin{array}{l}\text { Size fraction } \\
(\mu \mathrm{m})\end{array}$ & Description & Analysis techniques \\
\hline $\mathrm{R} 2 \mathrm{~B}$ & $\mathrm{R} 2 \mathrm{~B}$ & $0-3^{\mathrm{b}}$ & Bulk coatings & Coatings abraded off nonmag. frac. & $\begin{array}{l}\text { XRD, XAS, and } \\
\text { TEM }\end{array}$ \\
\hline $\mathrm{R} 2 \mathrm{~B} 1$ & $\mathrm{R} 2 \mathrm{~B}$ & $3-6^{\mathrm{c}}$ & $250-1000$ & Sized sedim., magnetic frac. & $\begin{array}{l}\mu \text {-XRD, XAS, SXRF } \\
\text { and SEM }\end{array}$ \\
\hline $\mathrm{R} 2 \mathrm{~B} 2$ & $\mathrm{R} 2 \mathrm{~B}$ & $3-6^{\mathrm{c}}$ & $250-1000$ & Sized sedim., nonmag. frac. & $\begin{array}{l}\mu \text {-XRD, XAS, SXRF } \\
\text { and SEM }\end{array}$ \\
\hline $\mathrm{R} 2 \mathrm{BX} 11$ & $\mathrm{R} 2 \mathrm{~B}$ & $3-6^{\mathrm{c}}$ & $125-1000$ & Sized sedim., nonmag. fraction & $\mu$-SXRF and SEM \\
\hline Z9A & Z9A & $0-3^{\mathrm{b}}$ & Bulk coatings & Coatings abraded off whole sedim. & XRD and XAS \\
\hline SIQ & Z5.7 & $0-6$ & $250-1000$ & $\begin{array}{l}\text { Clean, quartz sand incubated on streambed in slotted } \\
\text { PVC tube (Condon, 2003) }\end{array}$ & XRD and XAS \\
\hline AK1 & $\mathrm{AK} 1$ & $0-10^{\mathrm{b}}$ & Bulk coatings & Coatings abraded off whole sedim. & XAS \\
\hline
\end{tabular}

\footnotetext{
${ }^{\text {a }}$ Sampling depth in streambed.

${ }^{\mathrm{b}}$ Less than one millimeter surface sediment, scooped.

${ }^{\mathrm{c}}$ Streambed push-core interval.
} 
and $4670 \mathrm{ppm}$ for R2B and Z9A sites, respectively. The $\mathrm{HH}$-extracted Mn concentration of the AK1 bulk sediment was $3150 \mathrm{ppm}$. Replicates of HH extractions and total dissolutions of bulk sediments yield variability of $\pm 8 \%$ and $\pm 2 \%$ for $\mathrm{Mn}$ concentration, respectively. Metals content in the abraded coating fractions ( $\mathrm{R} 2 \mathrm{~B} / \mathrm{Z} 9 \mathrm{~A})$ as determined by $\mathrm{HH}$-extraction were $137,600 / 132,000 \mathrm{ppm}(\mathrm{Mn}), 1380 /$ 1290 ppm (Zn), 1920/1830 ppm (Co), 1590/1530 ppm (Cu), 630/650 ppm (Ni), 4180/3890 ppm (Fe), and 6470/ $5880 \mathrm{ppm}(\mathrm{Al})$. Total metals content from $\mathrm{HF}-\mathrm{HNO}_{3}$ digestion of abraded coatings provided similar values for all metals except for $\mathrm{Fe}(29,100 / 31,000 \mathrm{ppm})$ and $\mathrm{Al}$ $(58,200 / 56,950 \mathrm{ppm})$, indicating that $\mathrm{Fe}$ - and $\mathrm{Al}$-rich phases are also present in association with the coatings, and that trace metals are likely in association with the Mn oxides (Fuller and Harvey, 2000).

\subsubsection{Preparation for bulk analysis}

Analyses were conducted on bulk grain coatings recovered from wet grains to investigate the Mn oxide bulk mineralogy, including impacts from drying. Mn oxide coatings were abraded off of sediment grains by shaking about $20 \mathrm{~g}$ (dry weight) of the $<1$-mm size fraction surface sediments in an artificial stream water of similar major ion content and $\mathrm{pH}$ of the stream, but without dissolved metals (ASW, see Harvey and Fuller, 1998, for composition), followed by settling for one minute, and then decanting. Abraded sediments were rinsed three times, decanted, combined, and concentrated by centrifugation. This method removed about $20 \%$ of the Mn content of the bulk sand, $\sim 0.5 \%$ of the sand mass. No measurable release of Mn was detected in the ASW or rinses. Total carbon concentrations in streambed coatings were determined using a Carlo Erba NA1500 elemental analyzer (EA), calibrated with NIST standards (Manies et al., 2004). Total carbon is assumed to be dominantly organic carbon because of the low carbonate content of Pinal Creek sediments. Replicate analyses of samples agreed within $5 \%$ of each other. The bulk coatings contained total organic carbon of 3 and $2 \%$ (R2B and Z9A sites, respectively).

\subsubsection{Preparation for microbeam analysis}

Room-temperature air-dried streambed sediment $(<1 \mathrm{~mm}$ ) grains from the R2B, Z9A, and AK1 sites (Table 1) were cast into Scotchcast resin mounts by Spectrum Petrographics, Inc., Scotchcast resin was chosen because it has a low tendency to promote redox changes in samples under $\mathrm{X}$-ray illumination and is low in trace metals. Double-polished petrographic thin sections $(30 \mu \mathrm{m}$ thickness) of magnetic and non-magnetic fractions were separately prepared. To enable transmission micro-focused EXAFS and XRD measurements, all but one of the thin sections were subsequently removed from their glass slide backings by immersing in acetone for less than $1 \mathrm{~min}$ and carefully removing from slide using a razor blade. The delaminated thin sections were mounted on $0.0005^{\prime \prime}$ Kapton tape on an $\mathrm{Al}$ frame for micro-XAS and -XRD measurement. Mn oxide coatings on non-magnetic grains exhibited similar morphological characteristics, dimensions, and compositions as coatings on magnetic grains as judged by optical and scanning electron microscopy-EDS. The non-magnetic fraction was subsequently the focus of most of the spectroscopic analyses because (a) the abundant Fe, presence of background $\mathrm{Mn}$, and relatively high density of the magnetic fraction complicated bulk spectroscopic analysis, and (b) microprobe beam time was not sufficient to permit comprehensive analysis of both fractions.

\subsubsection{Mn oxide coatings formed in-situ on stream-incubated quartz (SIQ site)}

The origin and formation conditions of Mn oxide coatings on sediments collected from the R2B, Z9A, and AK1 sites was generally not known due to channel scouring and bed load redeposition. To obtain Mn oxide coatings formed at a known streambed location, cleaned quartz sand ( $<1 \mathrm{~mm}$ diameter Granusil 4095, Unimin Corp.) was incubated in a slotted PVC tube on the streambed at site SIQ (Fig. EA-1) from June 21 to November 27, 2001 (153 days) (Condon, 2003). This site is located about $150 \mathrm{~m}$ downstream of site 3 of Fuller and Harvey (2000) and $850 \mathrm{~m}$ upstream of site Z9A. The incubation tube was found buried in the streambed at the end of the period, likely from natural scour and deposition processes. The timing of this experiment was about 1.5 years after treated water was returned to the stream channel above the head of perennial flow. While the treated water had no measurable dissolved metals, as described above for the site AK1 sample, the remnant contaminant plume still contributed significant dissolved $\mathrm{Mn}^{2+}$ to the stream. The $\mathrm{pH}$ at the incubation site varied between 6.4 and 6.8 during the incubation. Dissolved Mn was $96 \mu \mathrm{M}$ in June; $91 \mu \mathrm{M}$ in August, and $60 \mu \mathrm{M}$ in November Dissolved $\mathrm{Co}, \mathrm{Ni}$ and $\mathrm{Zn}$ were below the ICP detection limit $(0.3 \mu \mathrm{M})$. Coatings were removed from the sand for bulk analysis using the abrading process described in Section 2.1.1. The resulting stream incubated quartz sand had $3030 \mathrm{ppm} \mathrm{Mn;} 35 \mathrm{ppm} \mathrm{Fe}$, and <2 ppm $\mathrm{Co}, \mathrm{Ni}, \mathrm{Cu}$, and $\mathrm{Zn}$ as determined by $\mathrm{HH}$-extraction. The material was stored frozen until use.

\subsection{Electron microscopy}

Carbon-coated epoxy-impregnated thin sections were analyzed by SEM-EDS in a JEOL 5600 full field emission scanning electron microscope operated at an energy of $15 \mathrm{keV}$. Because of the presence of the epoxy impregnation, the vacuum in the electron microscope is unlikely to have induced morphological changes in the samples. Elemental compositions of the $\mathrm{Mn}$ oxide coatings were estimated using electron stimulated energy dispersive spectroscopy (EDS) using X-ray fluorescence. The integrated counts of major cations ( $\mathrm{Mn}, \mathrm{Fe}, \mathrm{Ca}, \mathrm{Mg}, \mathrm{Si}$, and $\mathrm{Al}$ ) were determined for over 130 individual points from R2B sediment coatings on three sand grains. TEM samples were prepared from abraded R2B coatings, which were suspended in isopropanol at room temperature and subsequently ultrasonically dispersed. A droplet of the suspension was placed on a porous carbon film supported on a copper grid (200 mesh). TEM measurements were performed using a JEOL 1230 transmission electron microscope operating at $80 \mathrm{kV}$ at the Geballe Laboratory for Advanced Materials at Stan- 
ford University. High-resolution TEM imaging of the R2B coatings was carried out on a JEOL JEM2010F FASTEM field-emission gun high-resolution TEM/STEM instrument operating at $200 \mathrm{kV}$ in the Department of Earth and Planetary Sciences, University of New Mexico. Prior to HRTEM imaging, qualitative energy dispersive X-ray spectra of individual particles were obtained on the JEOL 2010F using an Oxford Instruments INCA 250 EDS system with a Pentafet ultrathin window detector. Digital images were obtained using the CCD camera on a GATAN GIF 200 system and were processed using GATAN Digital Microscopy Suite software. Fast Fourier transforms (FFT) of the high-resolution images were used to measure lattice spacings with an estimated $\pm 3 \%$ error. Details of HRTEM imaging techniques and image interpretation can be found in Buseck (1992) and Self (1992).

\subsection{X-ray imaging and structure techniques}

\subsubsection{Imaging}

Synchrotron $\mu$-X-ray fluorescence $(\mu$-SXRF) image maps of thin sections were recorded using monochromatic radiation at Advanced Light Source (ALS) beam line 10.3.2 (Marcus et al., 2004). X-ray energy was generally $10 \mathrm{keV}$. Beam size on the sample varied from $17 \mu \mathrm{m}$ (horizontal) $\times 5 \mu \mathrm{m}$ (vertical) full width at half-maximum (FWHM) to a minimum of $5 \times 5 \mu \mathrm{m}$. X-ray fluorescence data were recorded using a 7-element Ge solid-state detector (Canberra).

\subsection{2. $X$-ray diffraction}

Bulk XRD intensity data were collected on abraded Mn oxide coatings in transmission geometry at SSRL beam line 11-3 using a MAR 345 image plate detector $(150 \mu \mathrm{m}$ beam, $\lambda=0.975 \AA$ ). In all cases, calibration was maintained using diffraction from $\mathrm{LaB}_{6}$. Wet samples were placed in a transmission sample cell with Lexan windows. Bulk XRD data were corrected for variations in sample thickness as a function of $2 \theta$, and background contributions from Lexan windows and water in the sample were removed by subtraction. Micro-XRD ( $\mu$-XRD) intensity data were collected at ALS beam line 7.3.3 in transmission geometry (room temperature). A MAR CCD detector was used to record the data, binned into $512 \times 512$ or $1024 \times 1024$ pixels. Incident energy was set to $9 \mathrm{keV}(\lambda=1.378 \AA$ ). Exposure times varied from 3 to $15 \mathrm{~min}$. Typical beam size was $10 \mu \mathrm{m} \times 4 \mu \mathrm{m}$ at the sample. Micro-XRD intensity data backgrounds were fit and subtracted to remove scattering from Mn K fluorescence emission, air scattering, and other sources of low-frequency background variation. XRD maps were obtained by rastering the sample in front of the beam and recording XRD data at each point (Manceau et al., 2002).

\subsubsection{XANES and EXAFS spectroscopy}

Bulk Mn K-edge EXAFS and high-resolution XANES spectra from dry and wet sediment coatings were measured in transmission mode at room temperature at SSRL beam line 11-2 (variable-exit $\mathrm{Si}(220)$ monochromator). Harmonic content in the X-ray beam was attenuated by use of a collimating mirror set at $11.5 \mathrm{keV}$ and by detuning the mono- chromator. Samples were loaded into rigid thermoplastic sample holders with Lexan windows to maintain hydrated conditions (if necessary). Energy calibration was monitored using the pre-edge peak of $\mathrm{KMnO}_{4}(6543.34 \mathrm{eV})$. Beam dimension at the sample at BL $11-2$ was typically $5 \mathrm{~mm}$ (horizontal) $\times 0.5 \mathrm{~mm}$ (vertical), with a flux density of $c a$ $10^{10}$ photons/s. Reduction of $\mathrm{Mn}(\mathrm{IV})$ to $\mathrm{Mn}(\mathrm{II})$ was not observed. Mn K-edge (bulk) EXAFS were stable over several hour exposures, indicating that the unfocused X-ray beam at BL 11-2 did not damage the sample. Typically one or two EXAFS scans were measured on each sample (30-60 min).

Micro-EXAFS ( $\mu$-EXAFS) spectra were measured from delaminated thin-sections ( $c f$., Section 2.1.1) at room temperature in transmission geometry at the ALS beam line 10.3.2 ( $\mathrm{Si}(111)$ monochromator operated in variable-exit mode) at room temperature. $\mu$-EXAFS and $\mu$-XRD data generally were not measured at exactly the same points on the samples because it was necessary to record the data at different beam lines (i.e., $\mu$-EXAFS at ALS 10.3.2, and $\mu$ XRD at ALS 7.3.3). In spite of this, every effort was made to acquire $\mu$-XAS and $\mu$-XRD in proximal locations and especially from points on the same contiguous grain coatings. Beam dimensions for $\mu$-EXAFS were up to $17 \mu \mathrm{m} \times 5 \mu \mathrm{m}$ at the sample, whereas $\mu$-SXRF image maps were measured using a $5 \times 5-\mu \mathrm{m}$ beam. Multiple-scan exposure tests showed that reduction of $\mathrm{Mn}(\mathrm{IV})$ occurred to a detectable extent in the highly-focused X-ray beam after exposures as short as 20 or $30 \mathrm{~min}$. Consequently, Mn Kedge EXAFS were measured in a single scan $(\sim 25 \mathrm{~min})$ at each point. It was generally necessary to measure EXAFS spectra from coatings for which the minimal cross-sectional thickness was $\geqslant c a 10 \mu \mathrm{m}$ in order to obtain good quality, distortion-free spectra.

XANES transmission spectra were background-subtracted, normalized, and fit with linear combinations of spectra from acid birnessite and $\mathrm{Mn}^{2+}(\mathrm{aq})$ using SIXPACK/IFEFFIT (Newville, 2001; Webb, 2003). Other spectra attempted as references included: $\delta-\mathrm{MnO}_{2}$, synthetic manganite $(\gamma-\mathrm{MnOOH})$, groutite $(\alpha-\mathrm{MnOOH})$, synthetic feitknechtite $(\beta-\mathrm{MnOOH})$, bixbyite $\left((\mathrm{Mn}, \mathrm{Fe})_{2} \mathrm{O}_{3}\right)$, synthetic hausmannite $\left(\mathrm{Mn}_{3} \mathrm{O}_{4}\right)$, pyrolusite $\left(\beta-\mathrm{MnO}_{2}, \mathrm{Al}-\right.$ drich), nsutite $\left(\gamma-\mathrm{MnO}_{2}\right.$, Nsuta, Ghana), and synthetic todorokite $\left((\mathrm{Na}, \mathrm{Ca}, \mathrm{K})(\mathrm{Mg}, \mathrm{Mn}) \mathrm{Mn}_{6} \mathrm{O}_{14} \cdot 5 \mathrm{H}_{2} \mathrm{O}\right)$. Synthesis/ origin and identification of reference spectra were described in detail previously (Villalobos et al., 2003; Bargar et al., 2005). Estimated standard deviations (ESDs) for fits to Mn K-edge data were obtained by analysis of transmission spectra measured from a series of well defined mixtures of $\mathrm{MnSO}_{4}, \mathrm{Mn}_{2} \mathrm{O}_{3}$, and $\delta-\mathrm{MnO}_{2}$, diluted and homogenized into a $\mathrm{LiCO}_{3}$ matrix. Linear regression analyses of these references provided $1 \sigma$ error estimates: $1.7 \%$ for $\mathrm{Mn}(\mathrm{II})$ as $\mathrm{MnSO}_{4}, 2.6 \%$ for $\mathrm{Mn}(\mathrm{III})$ as $\mathrm{Mn}_{2} \mathrm{O}_{3}$, and $2.9 \%$ for $\mathrm{Mn}(\mathrm{IV})$ as acid birnessite. These values are distinct from and substantially larger than the fit-derived ESDs (which typically had values of $\sim 0.5 \%$ ). Thus, fit-derived ESDs are not reported.

EXAFS spectra were background-subtracted, normalized, and analyzed in SIXPACK/IFEFFIT. Phase and amplitude files for the EXAFS fitting were created with 
FEFF6 (Rehr et al., 1992). Mn EXAFS were fit using a model based on a phyllomanganate structure developed by Webb et al. (2005b), described below.

\section{RESULTS}

\subsection{X-ray diffraction}

\subsubsection{Bulk XRD data}

Background-subtracted XRD data for wet and dry Pinal Creek bulk coatings and for hexagonal birnessite are shown in Fig. 2 (bottom). All of these patterns exhibit a broad (0 0 1) reflection at $7.4 \AA$ (dry) or $10 \AA$ (wet), and a pair of strongly asymmetric peaks at ca 2.48 and $1.44 \AA$, which originate from the in-layer $(200) /(110)$ and $(310) /(020)$ birnessite reflections, typical of turbostratically disordered phyllomangantes (Reynolds, 1989; Villalobos et al., 2006). Turbostratic disorder implies that successive layers of the structure are rotated and sheared relative to one another, destroying long-range structural coherence. As a result, $(h k l)$ reflections having out-of-plane components are lost, but $(00 l)$ and $(h k 0)$ are preserved, although they may be asymmetrically broadened. The ratio of $d$ spacings for $(200) /(110)$ (i.e., half of the monoclinic $b$ axis length) and $(310) /(020)$ (i.e., half of the monoclinic a axis length) is expected to have a value of $\sqrt{ } 3$ if hexagonal symmetry is preserved in the layer (irrespective of the presence of turbostratic disorder). The ratio of $\mathrm{d}$ spacings for these reflections in the bulk samples (1.72) is in good agreement with hexagonal layer symmetry. Hexagonal symmetry also requires that the $(200) /(110)$ reflections share a common $d$ spacing, as do $(310) /(020)$. Loss of hexagonal symmetry would result in a monoclinic or triclinic unit cell. In addition to the pattern for turbostratic hexagonal birnessite, the bulk coating patterns also exhibit kaolinite/muscovite reflections at $c a 4.5,3.35,2.67$, and $1.5 \AA$, most intense in the Z9A patterns.

Each bulk coating sample was measured wet and dry. The (001) reflection was found to shift from $c a 10$ to $\sim 7.4 \AA$ upon air or oven drying (Fig. 1), negating todorokite (which possesses a $\sim 9.8-\AA$ reflection) as a possible phase assignment (Burns and Burns, 1979). The relative heights of peaks in the 2.48 - and $1.44-\AA$ regions are unaffected by drying, as expected for layer Mn oxides.

\subsection{2. $\mu-X R D$ data}

A representative 2-dimensional $\mu$-XRD pattern from the Mn oxide coatings is shown in Fig. EA-2. Two types of grain textures are evident in this pattern; well-defined diffraction spots arise from quartz grains. In sharp contrast to these points, continuous Scherrer rings are present at $\sim 7.1,2.48 \AA$, and a third, weak ring is also present at $1.42 \AA$. These $d$ spacings are characteristic of dehydrated birnessites (above). The continuity of the Scherrer rings indicates that the Mn oxide particles are unoriented and their effective average size is very small relative to the incident beam size $\left(40 \mu \mathrm{m}^{2}\right.$ cross-sectional area and $1200 \mu \mathrm{m}^{3}$ volume).

Integration of the $2 \mathrm{D} \mu-\mathrm{XRD}$ diffraction patterns around the Eulerian angle $\chi$ (i.e., around the Scherrer rings) provides 1D powder patterns (Fig. 2). All patterns contain a pair of peaks at $c a 2.48$ and $1.44 \AA$ that are consistent with hexagonal birnessite. About half of the $\mu$-XRD patterns exhibit a well defined basal plane reflection between 7.3 and $7.7 \AA$, consistent with a birnessite-like structure. The other half of the $\mu$-XRD patterns exhibit weak or absent $(001)$ reflections, indicating that the Mn oxides are either single-layer materials, or that the basal plane repeat distance is highly disordered (or both), so that no coherent basal plane reflection occurs (Reynolds, 1989). In the case that the oxides are only a few layers thick, these two explanations are likely to be equivalent; the oxides may be two or three layers thick, but do not have a coherent basal repeat distance and thus diffract as single-layer materials.

The relative intensity of the 2.48 - $\AA$ peak was mapped over portions of R2B2 grains 1 and 3 to assess the distribution of layered Mn oxides in these grains. Results are shown in Fig. 3. In both grain maps, well defined birnessite coatings $\sim 10$ to $30 \mu \mathrm{m}$ thick are observed to be coincident with the Mn coatings imaged by $\mu-S X R F$.

\subsection{Electron microscopy and $\mu-S X R F$ measurements of selected grains}

SEM and $\mu$-SXRF images from a representative Mnoxide coated R2B site quartz grain (R2B-X11) are shown in Fig. 4. A Mn oxide coating of thickness ranging from $<1$ to $c a 35 \mu \mathrm{m}$, is visible around the grain. The low brightness of the oxide coating relative to the quartz grain indicates that it has a lower density than the grain interior. As can be seen at $10,000 \times$ and $50,000 \times$ magnification, the relatively low density is due to an open arrangement of fibers or thin, wavy sheet-like minerals possessing radii of curvature as small as $\sim 100 \mathrm{~nm}$. TEM images of $\mathrm{Mn}$ oxide coatings abraded from R2B grains show these features to be mats of $\mathrm{Mn}$ oxide sheets (Fig. 5B). Numerous crystals are seen having in-plane diameters of $50-100 \mathrm{~nm}$ (e.g., Fig. 5A), with some sheets reaching lateral dimensions up to a few hundred nanometers (e.g., inset in Fig. 5A). Thin ( $c a 3 \mathrm{~nm}$ ) linear features with constant width can be interpreted as 3-nm-thick sheet edges (e.g., lower right-hand corner of Fig. 5C) or as folds in sheets. The thickness of a sheet must be less than half the thickness of the fold. Thus, a 3-nm thick fold would imply a Mn oxide having $c a$ two layers (each $7.4 \AA$ thick).

High-resolution TEM images of abraded Mn-oxide sediment grain coatings from the R2B site are shown in Fig. 6. Mn oxide basal planes oriented sub-parallel to the plane of the page are evident in the images. Lattice fringes exhibit $2.4 \AA$ spacings, consistent with the prominent $(200) /(110)$ atomic planes observed in the XRD data. Significant local distortion is apparent in the lattice as indicated by non-linearities and offsets in the lattice fringes and the presence of dark spots at lattice points, which are ascribed to layer $\mathrm{Mn}(\mathrm{IV})$ site vacancies. This assignment is tentative because the image was not taken at Scherzer defocus due to the problems of taking a through-focus sequence of very small grains that was drifting in $x, y$ and $z$ directions. The contrast in high-resolution images is extremely sensitive to focus and contrast reversals occur in moving through focus. 


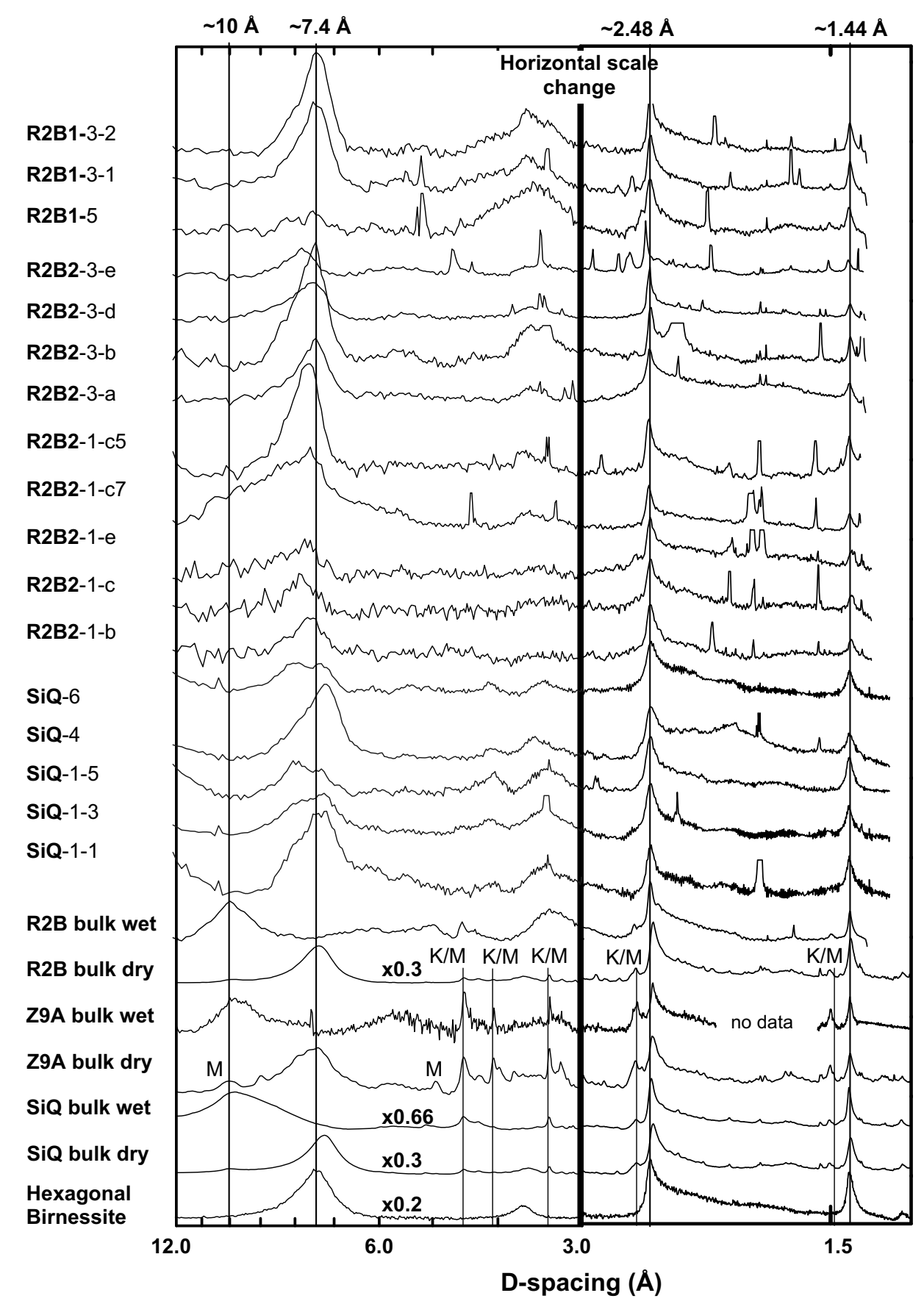

Fig. 2. XRD powder patterns of samples from Pinal Creek. Individual locations on grain coatings obtained by integrating 2D patterns are indicated by hyphenated sample names (top). Patterns from bulk samples are shown at bottom. Bold text labels refer to sample descriptions in Table 1. The first hyphenated numeric value refers to specific grains in these samples. The second hyphenated value refers to separate points (if any) in the referenced coating. Values preceded by " $x$ " denote vertical scaling of the data to facilitate comparison. Some intense point reflections from the original host grains (mostly quartz) have been truncated vertically to facilitate comparison of Mn oxide diffraction features. Vertical lines marked with, "M" or "K" give positions of muscovite or kaolinite lines. Other small peaks are quartz. Drying: All $\mu$ XRD samples, and dry bulk coatings were prepared by air-drying except for bulk SIQ, which was oven dried at $110^{\circ} \mathrm{C}$ for approximately 60 min. The horizontal scale changes at $3 \AA$ to provide an expanded view of the in-layer diffraction range between $\sim 1.2$ and $2.5 \AA$.

However, vacancies, distortion in the lattice, as well as the discontinuities in the periodicity of the lattice would be consistent with local displacement of atoms around layer Mn(IV) vacancies, which are observed in the EXAFS analyses (vide infra).
SEM-EDS and $\mu$-SXRF measurements were performed at multiple locations around the grains shown in Figs. 3 and 4 to assess correlations between $\mathrm{Mn}$ and $\mathrm{Ca}, \mathrm{Mg}, \mathrm{Al}$, and $\mathrm{Si}$. For the R2B-X11 grain, Ca was found to be correlated with $\mathrm{Mn}$. The Ca vs Mn correlation coefficient was 
Grain R2B2-01
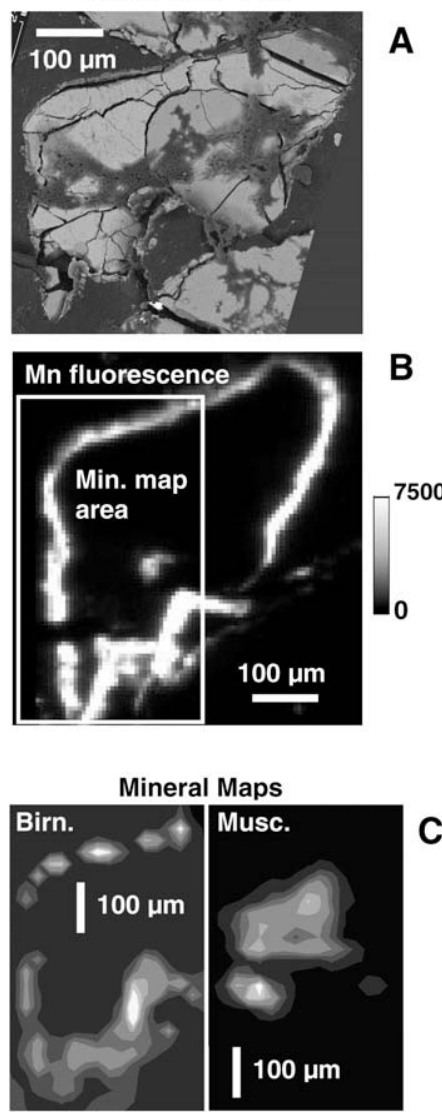

Grain R2B2-03
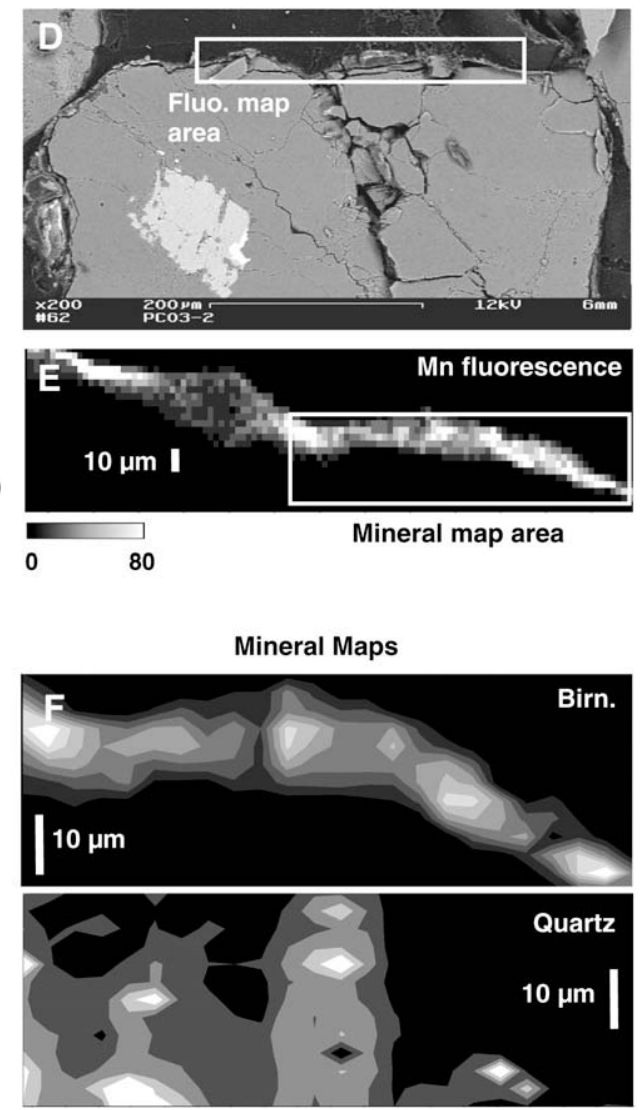

Fig. 3. Microdiffraction analyses of Pinal Creek grain coatings. (Panels A and D) SEM images. (Panels B and E) Mn fluorescence maps. (Panels C and F) mineral maps generated using 2.48 Å reflections (birnessite), $1.5 \AA$ reflections (muscovite, “Musc."), and $3.3 \AA$ A (quartz). The "beads on a string" apparent discontinuous structure of the top edge of grain 1 in the birnessite mineral map (Panel C) is a result of the relatively coarse scan step size and the subparallel alignment of the continuous grain edge relative to the scan axis. Full scale (white tone) for mineral maps (counts above background): R2B2-01 birnessite: 16, muscovite: 1200; R2B2-03 birnessite: 105, quartz: 35. Beam spot sizes used for maps: Grain 1 fluorescence map: 8 - $\mu \mathrm{m}$ step size $(7 \mu \mathrm{m}$ spot). Grain 1 mineral map: $20 \times 20 \mu \mathrm{m}$ vertical $\times$ horizontal step sizes $(3 \times 18 \mu \mathrm{m}$ spot). Grain 3 fluorescence map: $12-\mu \mathrm{m}$ step size $(3 \mu \mathrm{m}$ spot). Grain 3 mineral map: $3 \times 50-\mu \mathrm{m}$ step sizes $(4 \times 10 \mu \mathrm{m}$ spot $)$. Gamma value is 1.0 for all images.

$R=0.77$ (49 points), which is significant at the $99.8 \%$ confidence interval $(P<0.002)$. By comparison, $\mathrm{Mg}, \mathrm{Al}$, and $\mathrm{Si}$ were not significantly correlated with $\mathrm{Mn}$ in this grain ( $R=0.40,0.43$, and 0.12 , respectively). SEM-EDS measurements of grains R2B2-01 (30 points) and R2B2-03 (42 points, data not shown) also showed that Mn was well correlated to $\mathrm{Ca}(R=.89$ and .80 , respectively) and not significantly correlated to $\mathrm{Mg}, \mathrm{Al}$, and $\mathrm{Si}$. The SEM-EDS-derived ratios of Ca:Mn at.\% in coatings R2B-X11, R2B2-01, and R2B2-03 are $0.036 \pm 0.004, \quad 0.03 \pm 0.02$, and $0.040 \pm 0.008$, respectively. The correlation between $\mathrm{Ca}$ and $\mathrm{Mn}$ was also observed in $\mu$-SXRF measurements (Fig. 7). Ca vs Mn correlation plots of all data points in the $\mu$-SXRF images show two populations of points, labeled $\mathrm{Ca}^{\prime}$ and $\mathrm{Ca}$ " (Fig. 7, row 3). The $\mathrm{Ca}^{\prime}$ populations, which spatially correspond to the grain coatings, are well correlated with $\mathrm{Mn}(R=0.904$ and 0.898$)$. The $\mathrm{Ca}^{\prime \prime}$ images plot on the interior of grain 1 (muscovite) and on neighboring grains. The correlation between $\mathrm{Mn}$ and $\mathrm{Ca}$ suggests that $\mathrm{Ca}^{2+}$ is a structural interlayer cation in the Mn oxides.
This conclusion is generally consistent with prior reports noting the presence of the Ca-bearing birnessite takanelite in Pinal Creek Mn crusts (Bilinski et al., 2002).

\subsection{XANES and EXAFS spectroscopy}

\subsubsection{XANES}

Normalized XANES spectra from Pinal Creek bulk coatings and from micro-locations on individual grains are shown in Fig. EA-3. All major features of the spectra can be reproduced by fitting the spectra with two components: $\mathrm{Mn}(\mathrm{II})$ (indicated in the spectra by the 6553-eV shoulder on the low-energy side of the absorbance maxima), and a layered Mn oxide component, represented here by hexagonal birnessite (Fig. EA-3 and Table 2). There was no evidence for hausmannite or pure $\mathrm{Mn}$ (III) phases such as $\alpha-, \beta-$, or $\gamma-\mathrm{MnOOH}$ at detectable concentrations (e.g., greater than $\mathrm{ca} 5 \%$ of total Mn). XANES measurements are relatively insensitive to $\mathrm{Mn}$ (III) content when it is substituted into birnessite because there is little effect on 

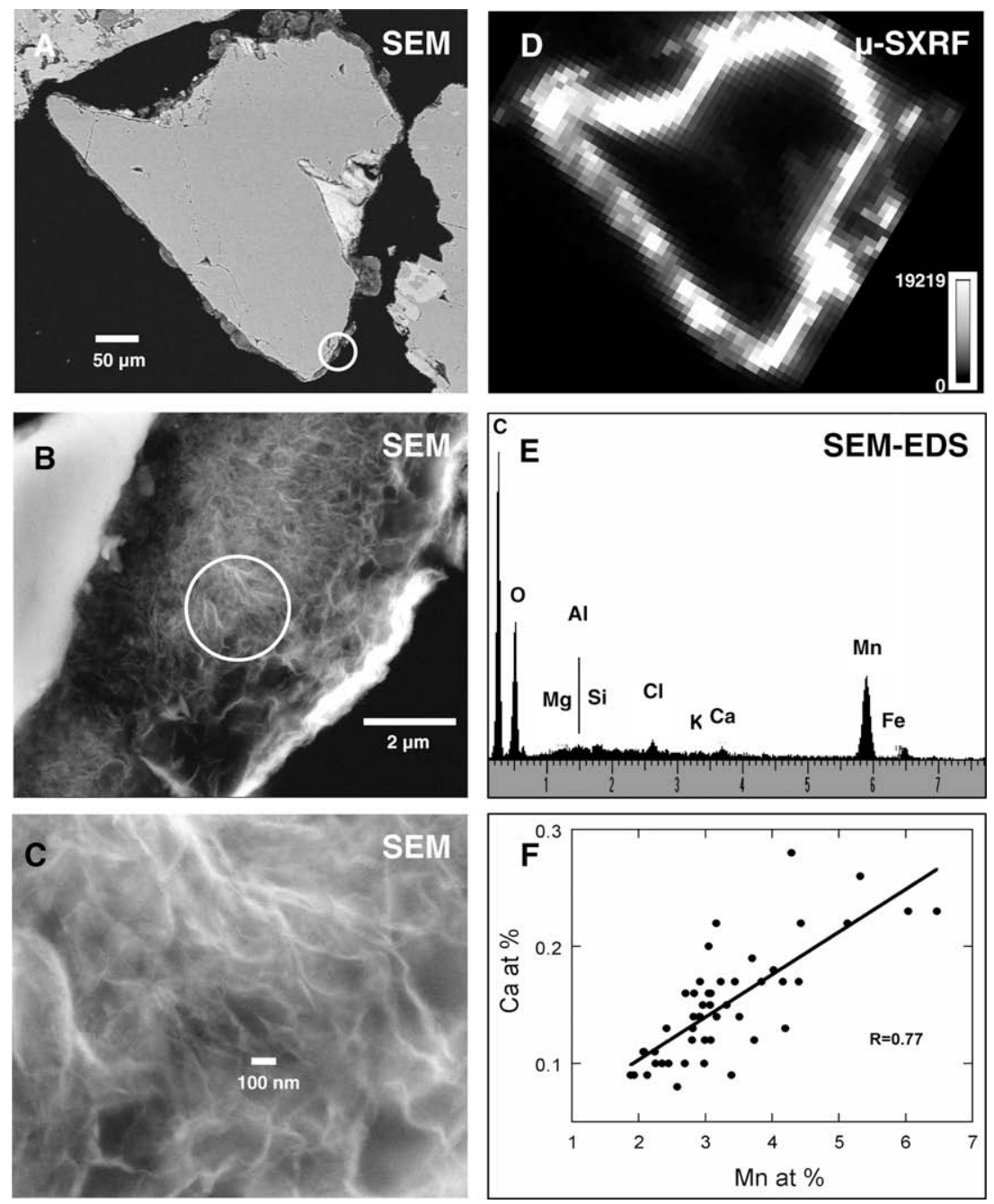

Fig. 4. Backscattered electron SEM (A, B, and C: $105 \times, 10,000 \times$, and 50,000× magnification, respectively) and $\mu$-SXRF (D) images of a representative Mn-oxide coated sediment grain from the R2B site (Gamma value $=1.0)$. $\mu$-SXRF image: $10-\mu \mathrm{m}$ steps, $7 \times 16 \mu \mathrm{m}$ spot (vertical $\times$ horizontal). $(\mathrm{B})$ and $(\mathrm{C})$ are zoomed images of the areas circled on (A) and (B), respectively. Image (D) shows the Mn fluorescence map of this grain, clearly illustrating the Mn oxide coating. (E) SEM-EDS spectrum from area indicated by circle in (B). (F) Correlation between $\mathrm{Mn}$ and $\mathrm{Ca}$ around the grain coating from SEM-EDS measurements.

the apparent position and structure of the $\mathrm{Mn} \mathrm{K}$-edge XANES spectra up to a Mn(III) content ca $30 \%$ of total Mn (Villalobos et al., 2003). Thus, the XANES results do not rule out the presence of $\mathrm{Mn}$ (III) in birnessite up to this value. XANES fits indicate that the bulk coatings contain on average $8 \% \mathrm{Mn}(\mathrm{II})$. This value is in relatively good agreement with an exchangeable Mn inventory of $6 \%$ of the total Mn oxide on streambed sediments collected in 1995 at site Z9A (Harvey and Fuller, 1998). XANES fits of the dried R2B bulk coatings (10.5\% Mn(II), Table 2) were similar to the results for the wet $\mathrm{R} 2 \mathrm{~B}$ coatings $(9.1 \%$ $\mathrm{Mn}(\mathrm{II})$ ), indicating that drying had only a minor effect on the oxidation state of $\mathrm{Mn}$ in the samples. The individual micro-locations on grain coatings contained about a 2.5 -fold greater amount of $\mathrm{Mn}(\mathrm{II})(15-27 \%, 20 \%$ average; Table 2). Repeat scans of the micro-locations ( $c f$., sample $\mathrm{H}$ ) indicated that beam-induced reduction of $\mathrm{Mn}(\mathrm{IV})$ to $\mathrm{Mn}(\mathrm{II})$ (seen only in micro-XAS measurements) in the 25-min duration of a single-EXAFS scan can produce a Mn(II) content increase of $c a 6 \%$ of total $\mathrm{Mn}\left(0.24 \% \mathrm{~min}^{-1}\right)$. XANES spectra are recorded during the initial $5 \mathrm{~min}$ of each EXAFS scan following an alignment procedure that requires up to $c a 5 \mathrm{~min}$ of dwell time on the sample location. It can thus be estimated that beam reduction can account for an increase in $\mathrm{Mn}(\mathrm{II})$ content of $\leqslant 2.4 \%$ of total $\mathrm{Mn}$. For this reason, beam reduction cannot account for the relative abundance of $\mathrm{Mn}(\mathrm{II})$ in the micro-locations as compared to the bulk. Measurement artifacts including pinhole/taper attenuation of the XANES and mismatch in beam line energy resolution between the data and reference spectra were tested for the ability to systematically increase the apparent $\mathrm{Mn}(\mathrm{II})$ content by quantitative modeling. These efforts were found to produce the same fit-derived $\mathrm{Mn}(\mathrm{II})$ content as obtained from the "uncorrected" spectra. Coatings that were chosen for micro-EXAFS analysis were generally among the thickest and most well-developed (typ- 

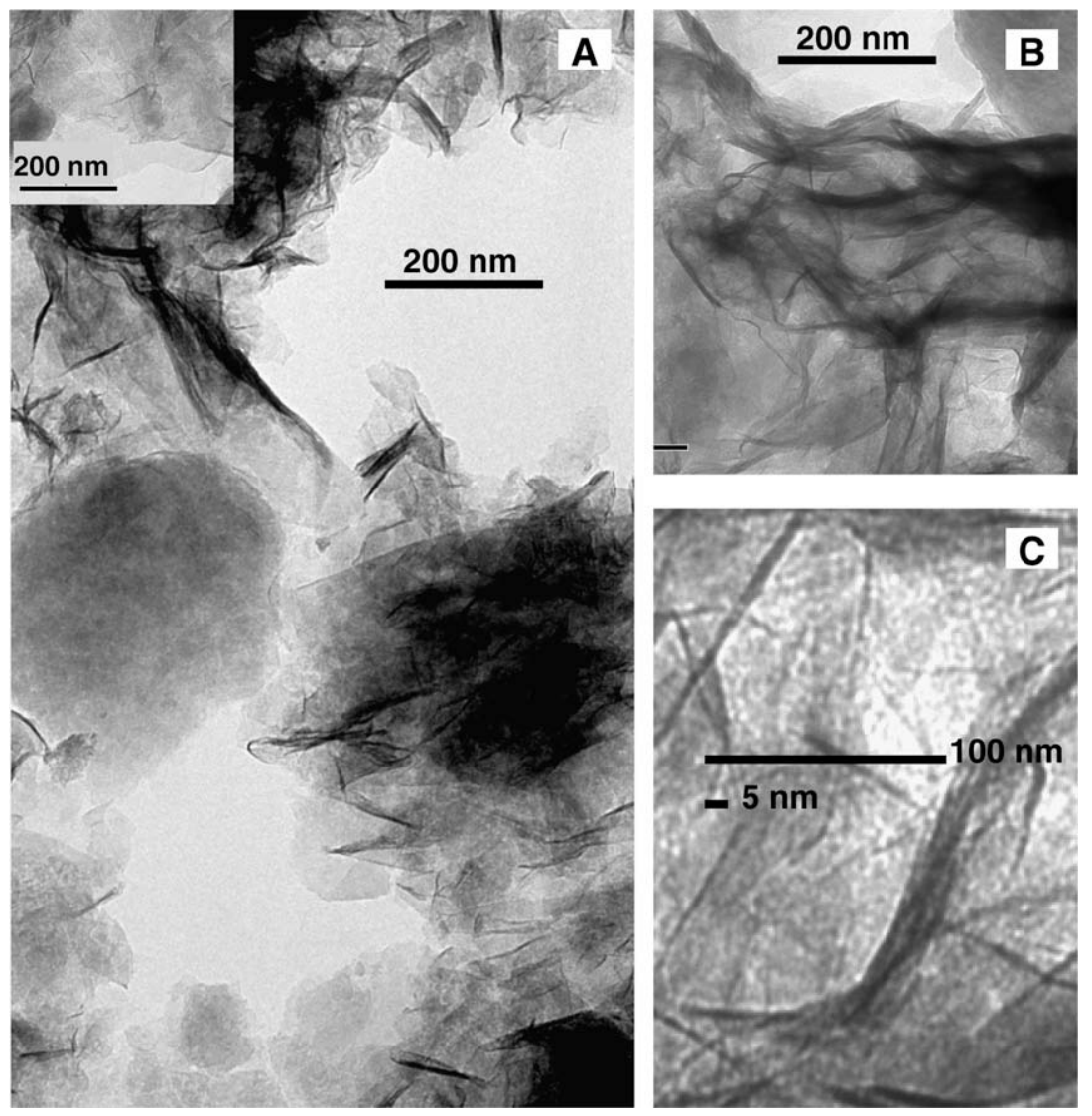

Fig. 5. (A-C) TEM images of abraded Mn-oxide sediment grain coatings from the R2B site. Note rumpled sheet-like morphology throughout.

ically $>10 \mu \mathrm{m})$, as necessary in order to record useable EXAFS spectra. We conclude that these thicker coatings apparently contain higher concentrations of $\mathrm{Mn}(\mathrm{II})$ than the bulk average.

Total $\mathrm{Mn}(\mathrm{II})$ concentrations reported as percentages in Table 2 have not been renormalized to a total of $100 \%$ because the proximity of the apparent sum to $100 \%$ (or the lack thereof) provides a measure of the appropriateness of the fit, selection of models, and the presence of artifacts such as sample inhomogeneities. In this case, the fit sums cluster around $100 \%$, with the largest deviation from this being $10 \%$, suggesting that the component selection was appropriate and samples were mechanically stable and reasonably homogeneous within the beam spot.

\subsubsection{EXAFS}

Background-subtracted $k^{3}$-weighted Mn K-edge EXAFS spectra from Pinal Creek bulk coatings and from micro-locations on individual grains are shown in Fig. 8. The top spectrum is that for acid birnessite, a layered Mn oxide possessing hexagonal layer symmetry (Villalobos et al., 2006). The abraded bulk coatings EXAFS spectra (A-D) are similar to that of hexagonal birnessite, in general agreement with the XRD results. Spectra and Fourier transforms (FTs) from micro locations on individual grain coatings ( $\mathrm{E}-$ J) are also similar to those of hexagonal birnessite with two important exceptions: the EXAFS antinode at $8 \AA^{-1}$ is attenuated or absent, as is the height of the corresponding $5.2 \AA(R+\delta R)$ peak in the Fourier Transforms. This is especially true of samples $\mathrm{G}$ and I, which resemble the spectra/FTs for triclinic $\mathrm{Na}$ birnessite as much as hexagonal birnessite (Fig. 8). The variation in height of these specific features originates in the planarity of the manganese oxide layer; tall narrow peaks at these positions are characteristic of Mn oxides with undistorted hexagonal layer symmetry and low Mn(III) content (Manceau et al., 2002, 2005; Webb et al., 2005b). These features arise from $\mathrm{Mn}-\mathrm{Mn}-\mathrm{Mn}$ multiple scattering, which dies away quickly as the $\mathrm{Mn}-\mathrm{Mn}-\mathrm{Mn}$ (i.e., linear adjacent $\mathrm{Mn}$ neighbors) angle bends away from $180^{\circ}$. Such bending can be induced by Jahn-Teller $(\mathrm{J}-\mathrm{T})$ distortion of layers when $\mathrm{Mn}(\mathrm{III})$ substitutes at otherwise undistorted layer $\mathrm{Mn}(\mathrm{IV})$ sites, such as occurs in triclinic Na-birnessite (Webb et al., 2005b), but not by the presence of Mn site vacancies or sheet edges.

Birnessites exhibit a rich variety of unit cell parameters, varying degrees of $\mathrm{Mn}$ (III) substitution at $\mathrm{Mn}$ (IV) layer sites, and varying $\mathrm{Mn}(\mathrm{IV})$ layer vacancy contents e.g., (Lanson et al., 2000, 2002a,b; Webb et al., 2005b,c; Villalobos et al., 2006). This behavior suggests the need for a data analysis approach that can account for sample-to-sample differences in structural parameters within layered Mn oxides. A shell-by-shell fitting approach was adopted, which was based on the birnessite EXAFS model of Webb et al. (2005b). This model is discussed in detail in the cited refer- 


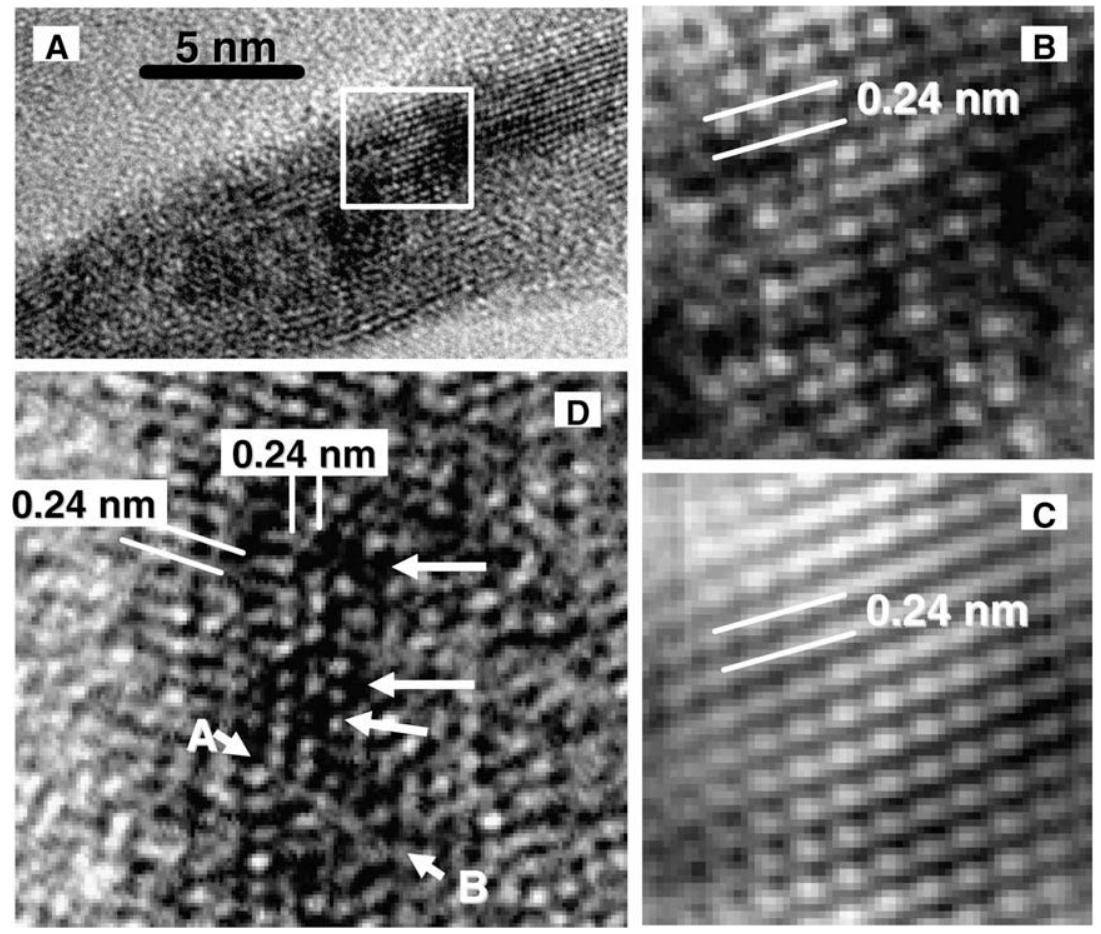

Fig. 6. TEM images of abraded Mn-oxide sediment grain coatings from the R2B site. (A) High-magnification bright field TEM image of a fold of Mn oxide sheet (looking down on the basal plane). (B) High-resolution TEM image of the boxed region in (A) showing lattice fringes with 0.24-nm spacings. (C) Fourier-filtered image of (B) to show the lattice periodicity with the noise removed. Note that the sheet fold axis is parallel to the monoclinic $b$ unit cell axis. (D) High-resolution TEM image of a birnessite basal plane illustrating the highly defective structure. The $0.24-\mathrm{nm}(200) /(110)$ lattice planes are oriented vertically in the image and are defined by the linear arrays of white dots. Individual white spots show small displacements from a perfectly linear array. The periodic arrays of white dots parallel to (200)/(110) are disrupted locally by the presence of distinct dark regions in the image, which may represent layer $\mathrm{Mn}(\mathrm{IV})$ vacancies. A defect which offsets the $(200) /(110)$ lattice planes is also indicated by the arrows labeled A and B.

ence and is summarized here. It is based upon the basic hexagonal layered Mn oxide structure (Fig. 1) and explicitly accounts for: (a) attenuation of $\mathrm{Mn}-\mathrm{Mn}-\mathrm{Mn}$ linear multiple scattering paths by out-of-plane rumpling of the structure believed to be caused by substitution of $\mathrm{Mn}$ (III) at layer $\mathrm{Mn}(\mathrm{IV})$ sites. The angular out-of-plane bending parameter, $\beta\left(0 \leqslant \beta \leqslant 20^{\circ}\right)$, which is the complement of $180^{\circ} \mathrm{Mn}-\mathrm{Mn}-$ $\mathrm{Mn}$ vector has a minimum value of $0^{\circ}$ in flat hexagonal sheets (at which point there is no attenuation of linear multiple scattering) and increases as the layers becomes rumpled. At values $>0^{\circ}$, multiple scattering is attenuated as predicted by theory. The model also accounts for (b) splitting of the $\mathrm{Mn}-\mathrm{O}$ shell into 4 short/2 long $\mathrm{Mn}-\mathrm{O}$ bonds as is believed to occur in layer Mn oxides due to $\mathrm{J}-\mathrm{T}$ distortion (Lanson et al., 2002a); (c) splitting of in-layer Mn-Mn distances due to $\mathbf{J}-\mathbf{T}$ distortion of the first shell or to loss of hexagonal layer symmetry; (d) the presence of particle edge terminations layer and layer Mn(IV) site vacancies, believed to be present in biogenic and hexagonal layered Mn oxides (Villalobos et al., 2006), which linearly attenuate the intensity of all Mn shells (i.e. at 2.8, 4.8, and $5.7 \AA$ ) by a similar factor (this behavior is different from rumpling of layers, which specifically attenuates the $5.7 \AA$ shell but not those at 2.8 and $4.8 \AA$ ); and (e) the presence of sorbed $\mathrm{Mn}(\mathrm{II})$, which has little to no extended local structure and hence dilutes the signal from the birnessite 2 nd and higher shell fea- tures. In the present work, fits to EXAFS spectra were truncated at $k=12 \AA^{-1}$ because of the presence of the $\mathrm{Fe}$ K-edge absorbance at $12.2 \AA^{-1}$. Reducing the data range from $15 \AA^{-1}$, the data range used to develop the Webb model, reduces the total constraints available. For this reason, the full model of Webb et al. (2005b) was restricted to fitting the following subset of atomic shells (labeled in accordance with the cited reference) (cf., Fig. 1): O $(\sim 1.9 \AA), \mathrm{Mn}_{1}(\sim 2.85 \AA), \mathrm{Mn}_{\text {corner }}(\sim 3.5 \AA)$, which correspond to $\mathrm{Mn}$ atoms (likely to be $\mathrm{Mn}$ (II) or (III)) tightly bonded to the surface of the octahedral sheet above Mn site vacancies (Webb et al., 2005b), $\mathrm{Mn}_{2}$ ( $\sim 4.8 \AA$ ), $\mathrm{Mn}_{3}$ ( $\sim 5.7 \AA)$, and aqueous/sorbed $\mathrm{Mn}(\mathrm{II})\left(\mathrm{Mn}_{\mathrm{II}}-\mathrm{O} \sim 2.25 \AA\right.$ ) . The proportion of aqueous $\mathrm{Mn}$ (II) was fixed from the XANES fits for all Pinal Creek samples. The triclinic birnessite model was found to have about $10 \% \mathrm{Mn}$ (II). O, $\mathrm{Mn}_{1}, \mathrm{Mn}_{2}$, and $\mathrm{Mn}_{3}$ shells were allowed to split into two subshells to account for in-layer monoclinic distortion that occurs in triclinic layered $\mathrm{Mn}$ oxides in response to $\mathrm{J}-\mathrm{T}$ distortion (Webb et al., 2005b). Coordination numbers (CN) for $\mathrm{O}, \mathrm{Mn}_{1}, \mathrm{Mn}_{2}$, and $\mathrm{Mn}_{3}$ were fixed to the value of 6 (for each shell) as dictated by the layered Mn oxide structure. Shortfalls of the $\mathrm{CN}$ of the $\mathrm{Mn}_{1}, \mathrm{Mn}_{2}$, and $\mathrm{Mn}_{3}$ shells as compared to the value of 6 may occur if layer $\mathrm{Mn}(\mathrm{IV})$ sites are vacant or if edge sites are significant (Webb et al., 2005b). 


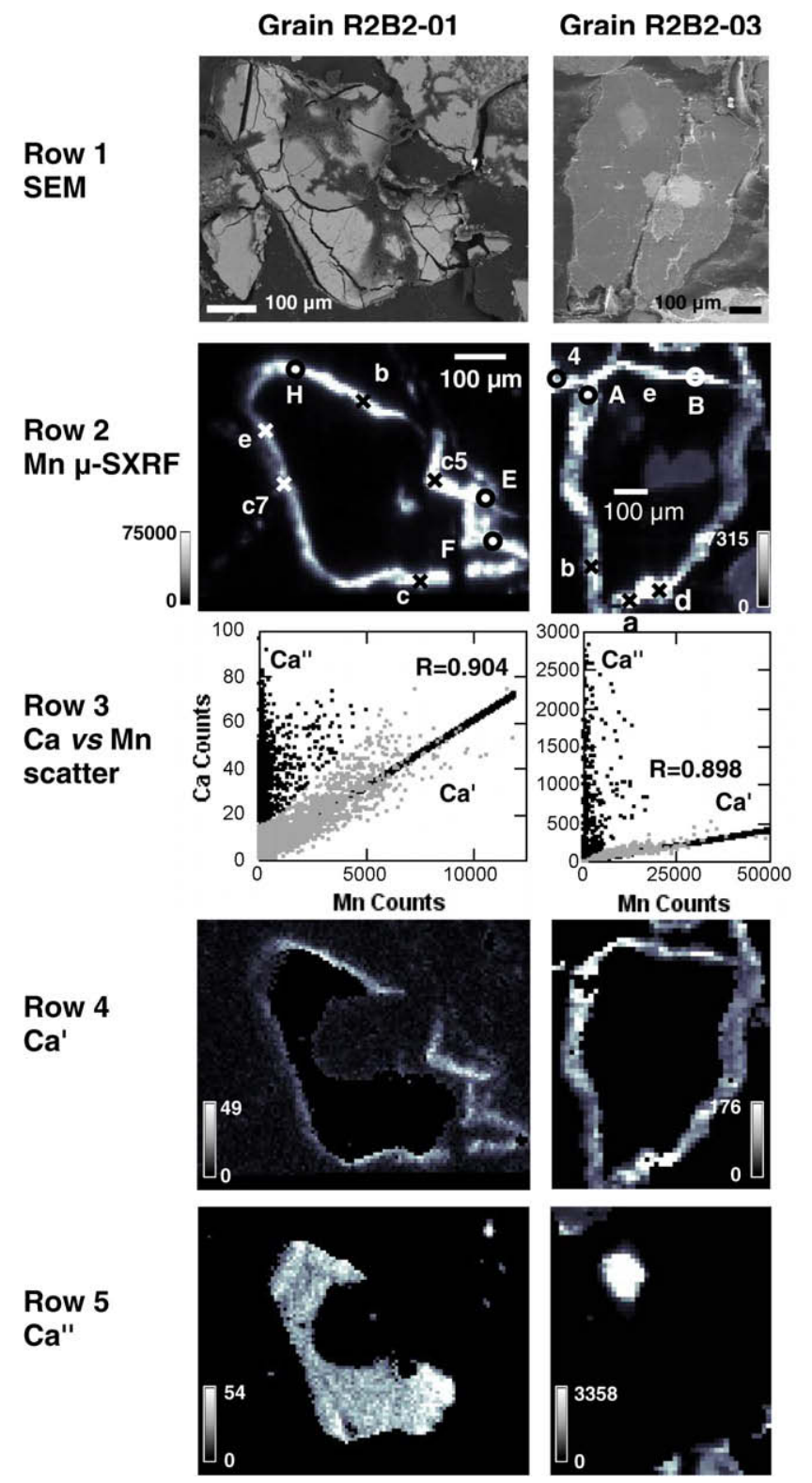

Fig. 7. Correlation between $\mathrm{Mn}$ and $\mathrm{Ca}$ in Pinal Creek grain coatings as measured by $\mu$-SXRF. Row 1: SEM images. Row 2: Mn fluorescence maps. Capitalized letter labels: $\mu$-XAS data points. Lower case letters: $\mu$-XRD locations. Row 3: Ca vs Mn scatter plots. Grey scatter plot points show those pixels masked to identify the population labeled as $\mathrm{Ca}^{\prime}$. Points outside of this mask (black) are labeled as $\mathrm{Ca}^{\prime \prime}$. Rows 4 and 5 : images of $\mathrm{Ca}^{\prime}$ and $\mathrm{Ca}^{\prime \prime}$ populations. Beam spot sizes used for maps: $7 \mu \mathrm{m}$. Grain 1 map: 8- $\mu \mathrm{m}$ step size; grain 3 map: $15-\mu \mathrm{m}$ step size. Gamma value is 1.0 for all maps.

This modeling approach, i.e., fixing the $\mathrm{CN}$ to 6 , based on the birnessite structure, and splitting the sub-shells in the specific manner prescribed by $\mathrm{J}-\mathrm{T}$ distortion, i.e., into two sub-shells: 4 short $\mathrm{Mn}-\mathrm{O}$ bonds and 2 long, leaves only $R$ and $\sigma^{2}$ values (only weakly correlated) to be determined. The latter can be evaluated by fitting as for other shells, as indicated by the reasonable uncertainties obtained (Table 3). $R$ values for each sub-shell can be evaluated using this model because the EXAFS amplitude and corresponding net $\mathrm{Mn}-\mathrm{O}$ shell FT peak height is highly sensitive to the distance between the short and long $\mathrm{Mn}-\mathrm{O}$ bonds, due to destructive interference be- tween the EXAFS signal from the split sub-shells. A $0.05-\AA$ split reduces the $\mathrm{Mn}-\mathrm{O}$ FT peak amplitude by $10 \%$, whereas a $0.1 \AA$ splitting removes $30 \%$ of the amplitude of the unsplit shell (Webb et al., 2005b). Case in point; the heights of the Mn-O FT peaks in the microEXAFS series vary by up to $60 \%$ (the FT peak heights for the bulk data vary by $14 \%$ ). In the absence of any other information, this height variation would imply a $60 \%$ change in the coordination number, e.g., from 6 to $3.6 \mathrm{O}$ atoms in the 1 st coordination shell. Such a variation is highly unlikely considering that $\mathrm{Mn}(\mathrm{IV})$ ubiquitously occurs in octahedral coordination in oxides (Post, 
Table 2

Results from linear combination fits to XANES using spectra for hexagonal birnessite and $\mathrm{Mn}^{2+}$ (aq). Values are mole $\%$ of total manganese present. Estimated standard deviations for fit-derived values are $\pm 1.7 \%$ for $\mathrm{Mn}(\mathrm{II})$ and $\pm 2.9 \%$ for hexagonal birnessite (cf, Section 2.3 .3 ). Average value for micro-XANES points excludes repeat sample $\left(\mathrm{H}_{\mathrm{r}}\right)$

\begin{tabular}{lllrr}
\hline Label & Sample & Hexagonal Birnessite & Mn(II) & Sum \\
\hline A & R2B bulk coatings & 90.7 & 9.1 & 99.8 \\
A $_{\text {dry }}$ & R2B bulk coatings, dried & 92.7 & 10.5 & 1.9 \\
B & Z9A bulk coatings & 96.6 & 5.4 & 103.2 \\
C & SIQ bulk coatings & 98.2 & 10.3 & 103.5 \\
D & AK1 bulk coatings & 88.8 & 8.2 & 19.2 \\
& Ave. bulk coatings & 93.6 & 19.0 & 10.1 \\
E & R2B2 grain 1 pt. H & 85.7 & 24.6 & 104.9 \\
F & R2B2 grain 1 pt. F & 84.2 & 20.8 & 103.2 \\
G & R2B2 grain 1 pt. E & 75.6 & 27.1 & 100.2 \\
H & R2B2 grain3 pt. B & 87.7 & 14.5 & 108.5 \\
H & Grain 3 pt. B repeat scan & 81.4 & 14.7 & 108.5 \\
I & R2B2 grain 3 pt. A & 90.3 & 20.0 & 104.8 \\
J & R2B2 grain 4 & 95.3 & & 110.0 \\
& Ave. individual points & 85.7 & & 105.7 \\
\hline
\end{tabular}
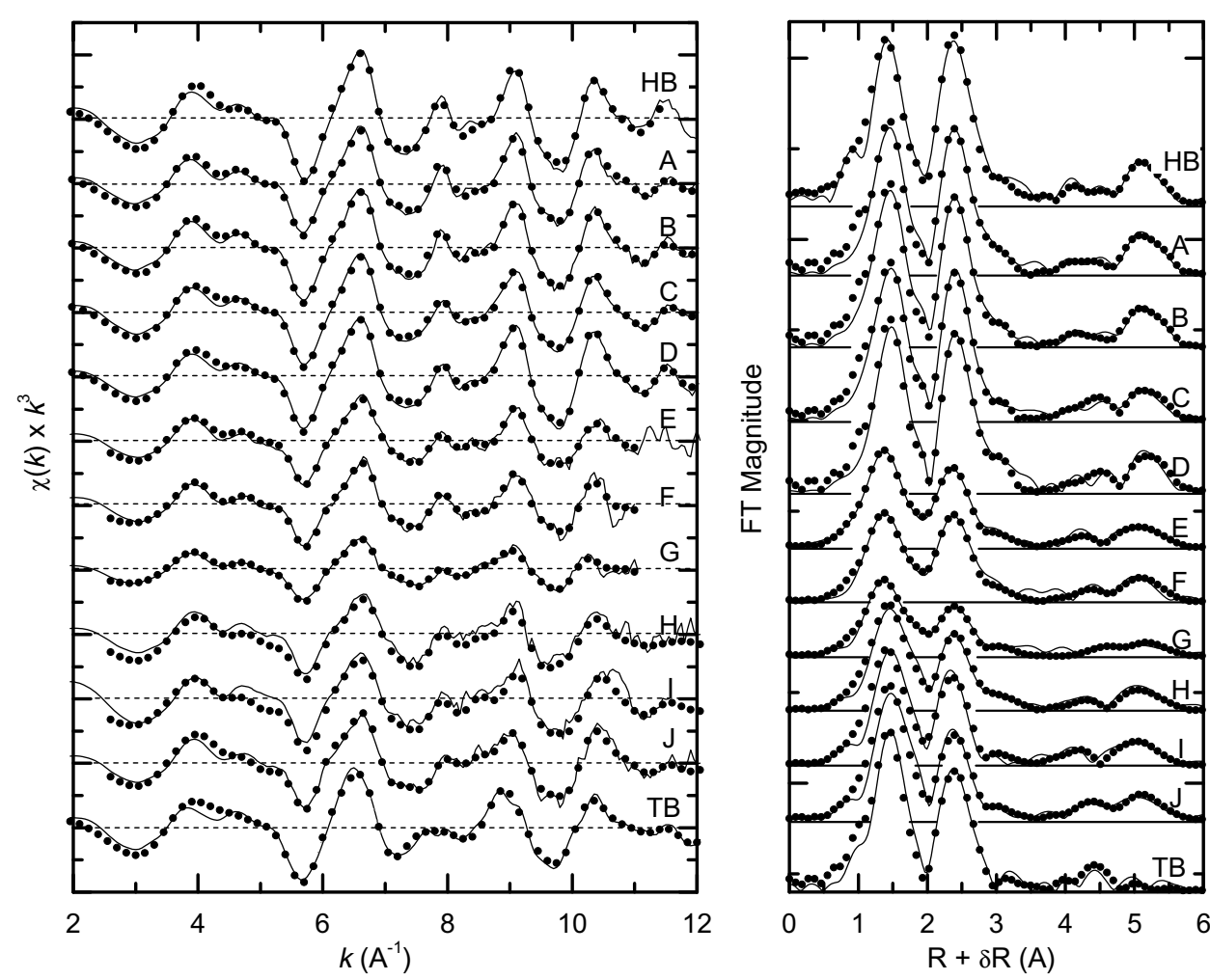

Fig. 8. EXAFS spectra and Fourier transforms from Pinal Creek samples (solid lines). Sample HB is hexagonal birnessite, whereas TB is triclinic birnessite. Other sample labels correspond to labels in Tables 2 and 3. Fits are represented by dotted lines.

1999). If the Mn-O FT peak heights from these spectra are plotted against the EXAFS fit-derived $\mathrm{O}$ shell splitting, then a strong inverse correlation $(R=0.94)$ is obtained (Fig. EA-4). This is behavior is in line with expectation and indicates that the EXAFS model behaves rationally. As a result of explicitly incorporating these two key constraints (i.e., that the $\mathrm{Mn}-\mathrm{O}$ shell splits into two components and the $\mathrm{Mn}-\mathrm{O} \mathrm{CN}$ must to sum to 6), the minimum resolvable distance between neighboring $\mathrm{O}$ shells that can be distinguished by the fits is expected to be governed primarily by the fit-derived uncertainties in $\mathrm{R}$ and not by $\delta R=\pi / 2 \times \delta k$ (Webb et al., 2005b).

$\mathrm{CNs}$ for $\mathrm{Mn}-\mathrm{Mn}$ shells also were fixed to 6. Amplitude shortfalls in Mn shells beyond that generated by splitting is accounted for in the model by defining a Mn site occupancy factor for layer $\mathrm{Mn}(\mathrm{IV})$ sites, $f_{\text {occ }}\left(0 \leqslant f_{\text {occ }} \leqslant 1\right)$, which lowers the effective $\mathrm{CN}$ of the $\mathrm{Mn}$ shells and which is allowed to vary in fits. Distances to the $\mathrm{Mn}_{3}$ shell are calculated explic- 
Table 3

EXAFS fit results. Alphabetically ordered sample labels correspond to Table $2 .{ }^{\dagger}$ Statistical $R$ factor. ${ }^{\dagger} \mathrm{Mn}$ in this shell is bonded above Mn(IV) layer site vacancies. Values in parentheses signify uncertainty in last digit. $f_{o c c}$ is fractional $\mathrm{Mn}$ site occupancy, $\beta$ is the out-of-plane bending angle, CN is coordination number, $R$ is interatomic distance $(\AA)$, and $\sigma^{2}$ is the Debye-Waller factor $\left(\AA^{2}\right)$. ${ }^{*}$ Uncertainty in $R_{\mathrm{Mn}-\mathrm{O} / \mathrm{Mn}}$ for each of subshells is larger than $\Delta R$ for this shell when split, hence shell was subsequently fit as single shell.

\begin{tabular}{|c|c|c|c|c|c|c|c|}
\hline Sample & $R^{\dagger}$ & $f_{\text {occ }}$ & $\beta\left(^{\circ}\right)$ & Shell & $\mathrm{CN}$ & $R_{\mathrm{Mn}-\mathrm{O} / \mathrm{Mn}}$ & $\sigma^{2}$ \\
\hline $\begin{array}{l}\mathrm{A} \\
\mathrm{R} 2 \mathrm{~B} \\
\text { bulk coatings } \\
k=2.6-11.9 \AA^{-1}\end{array}$ & 0.0164 & $.73(7)$ & $3(5.8)$ & $\begin{array}{l}\mathrm{Mn}-\mathrm{O} \\
\mathrm{Mn}-\mathrm{O} \\
\mathrm{Mn}-\mathrm{Mn}_{1} \\
\mathrm{Mn}-\mathrm{Mn}_{1} \\
\mathrm{Mncor}^{\ddagger} \\
\mathrm{Mn}-\mathrm{Mn}_{2} \\
\mathrm{Mn}-\mathrm{Mn}_{2} \\
\mathrm{Mn}-\mathrm{Mn}_{3} \\
\mathrm{Mn}-\mathrm{Mn}_{3} \\
\mathrm{MnII}-\mathrm{O}\end{array}$ & $\begin{array}{l}4 \\
2 \\
2 \\
4 \\
1.1(4) \\
4 \\
2 \\
2 \\
4 \\
6\end{array}$ & $\begin{array}{l}1.87(2) \\
1.91(3) \\
2.83(5) \\
2.87(6) \\
3.51(2) \\
4.87(4) \\
5.00(7) \\
5.67 \\
5.73 \\
2.25(9)\end{array}$ & $\begin{array}{l}0.009(3) \\
0.002(1) \\
0.004(1) \\
0.004 \\
0.004 \\
0.008 \\
0.01 \\
0.009\end{array}$ \\
\hline $\begin{array}{l}\mathrm{B} \\
\text { Z9A } \\
\text { bulk coatings } \\
k=2.6-11.9 \AA^{-1}\end{array}$ & 0.0096 & $.72(6)$ & $2(4.4)$ & $\begin{array}{l}\mathrm{Mn}-\mathrm{O} \\
\mathrm{Mn}-\mathrm{O} \\
\mathrm{Mn}-\mathrm{Mn}_{1} \\
\mathrm{Mn}-\mathrm{Mn}_{1} \\
\text { Mncor } \\
\text { Mn-Mn } \\
\mathrm{Mn}-\mathrm{Mn}_{2} \\
\mathrm{Mn}-\mathrm{Mn}_{3} \\
\mathrm{Mn}-\mathrm{Mn}_{3} \\
\mathrm{MnII}-\mathrm{O}\end{array}$ & $\begin{array}{l}4 \\
2 \\
2 \\
4 \\
0.9(3) \\
4 \\
2 \\
2 \\
4 \\
6\end{array}$ & $\begin{array}{l}1.85(1) \\
1.93(2) \\
2.83(4) \\
2.87(5) \\
3.49(2) \\
4.90(4) \\
5.02(7) \\
5.67 \\
5.73 \\
2.25(6)\end{array}$ & $\begin{array}{l}0.006(2) \\
0.0010(8) \\
0.0044(9) \\
0.0044 \\
0.0044 \\
0.008 \\
0.01 \\
0.006\end{array}$ \\
\hline $\begin{array}{l}\mathrm{C} \\
\mathrm{SiQ} \\
\text { bulk coatings } \\
k=2.6-12.0 \AA^{-1}\end{array}$ & 0.0190 & $.75(7)$ & $1(4.0)$ & $\begin{array}{l}\mathrm{Mn}-\mathrm{O} \\
\mathrm{Mn}-\mathrm{O} \\
\mathrm{Mn}-\mathrm{Mn}_{1}{ }^{*} \\
\mathrm{Mn}-\mathrm{Mn}_{1} \\
\text { Mncor } \\
\mathrm{Mn}^{\ddagger}-\mathrm{Mn}_{2} \\
\mathrm{Mn}-\mathrm{Mn}_{2} \\
\mathrm{Mn}-\mathrm{Mn}_{3} \\
\mathrm{Mn}-\mathrm{Mn}_{3} \\
\mathrm{MnII}-\mathrm{O}\end{array}$ & $\begin{array}{l}4 \\
2 \\
6 \\
0 \\
0.8(3) \\
4 \\
2 \\
6 \\
0 \\
6\end{array}$ & $\begin{array}{l}1.85(1) \\
1.93(2) \\
2.861(5) \\
- \\
3.49(2) \\
4.90(2) \\
5.04(6) \\
5.72 \\
- \\
2.25(12)\end{array}$ & $\begin{array}{l}0.007(2) \\
0.0008(8) \\
0.0053(7) \\
- \\
0.0053 \\
0.008 \\
0.008 \\
0.01 \\
- \\
0.007\end{array}$ \\
\hline $\begin{array}{l}\mathrm{D} \\
\text { AK1 } \\
\text { bulk coatings } \\
k=2.6-12.0 \AA^{-1}\end{array}$ & 0.018 & $.69(7)$ & $5(3.2)$ & $\begin{array}{l}\mathrm{Mn}-\mathrm{O} \\
\mathrm{Mn}-\mathrm{O} \\
\mathrm{Mn}-\mathrm{Mn}_{1} \\
\mathrm{Mn}-\mathrm{Mn}_{1}{ }^{*} \\
\mathrm{Mncor}^{\ddagger} \\
\mathrm{Mn}-\mathrm{Mn}_{2} \\
\mathrm{Mn}-\mathrm{Mn}_{2} \\
\mathrm{Mn}-\mathrm{Mn}_{3} \\
\mathrm{Mn}-\mathrm{Mn}_{3} \\
\mathrm{MnII}-\mathrm{O}\end{array}$ & $\begin{array}{l}4 \\
2 \\
6 \\
0 \\
1.1(4) \\
4 \\
2 \\
6 \\
0 \\
6\end{array}$ & $\begin{array}{l}1.87(2) \\
1.92(4) \\
2.863(6) \\
- \\
3.49(2) \\
4.91(5) \\
5.03(8) \\
5.72 \\
- \\
2.23(7)\end{array}$ & $\begin{array}{l}0.006(3) \\
0.001 \\
0.0037(8) \\
- \\
0.0037 \\
0.008 \\
0.008 \\
0.01 \\
- \\
0.006\end{array}$ \\
\hline $\begin{array}{l}\mathrm{E} \\
\mathrm{R} 2 \mathrm{~B} 2 \\
\text { grain } 1 \mathrm{pt} . \mathrm{H} \\
k=2.6-11 \AA^{-1}\end{array}$ & 0.0081 & $.67(7)$ & $10(5)$ & $\begin{array}{l}\mathrm{Mn}-\mathrm{O} \\
\mathrm{Mn}-\mathrm{O} \\
\mathrm{Mn}-\mathrm{Mn}_{1} \\
\mathrm{Mn}-\mathrm{Mn}_{1} \\
\text { Mncor } \\
\mathrm{Mn}^{*}-\mathrm{Mn}_{2} \\
\mathrm{Mn}-\mathrm{Mn}_{2} \\
\mathrm{Mn}-\mathrm{Mn}_{3} \\
\mathrm{Mn}-\mathrm{Mn}_{3} \\
\mathrm{MnII}-\mathrm{O}\end{array}$ & $\begin{array}{l}4 \\
2 \\
2 \\
4 \\
1.0(3) \\
4 \\
2 \\
2 \\
4 \\
6\end{array}$ & $\begin{array}{l}1.855(6) \\
1.986(4) \\
2.80(2) \\
2.88(2) \\
3.49(1) \\
4.86(4) \\
5.12(9) \\
5.59 \\
5.73 \\
2.26(1)\end{array}$ & $\begin{array}{l}0.004(1) \\
0.004 \\
0.0047(9) \\
0.0047 \\
0.0047 \\
0.008 \\
0.01 \\
0.004\end{array}$ \\
\hline $\begin{array}{l}\mathrm{F} \\
\text { R2B2 } \\
\text { grain 1 pt. F } \\
k=2.6-11 \AA^{-1}\end{array}$ & 0.0219 & $.62(11)$ & $6.5(12)$ & $\begin{array}{l}\mathrm{Mn}-\mathrm{O} \\
\mathrm{Mn}-\mathrm{O} \\
\mathrm{Mn}-\mathrm{Mn}_{1} \\
\mathrm{Mn}-\mathrm{Mn}_{1} \\
\text { Mncor }\end{array}$ & $\begin{array}{l}4 \\
2 \\
2 \\
4 \\
1.0(5)\end{array}$ & $\begin{array}{l}1.86(1) \\
1.98(6) \\
2.83(6) \\
2.87(9) \\
3.51(3)\end{array}$ & $\begin{array}{l}0.005(3) \\
0.005 \\
0.005(2) \\
0.005 \\
0.005\end{array}$ \\
\hline
\end{tabular}




\begin{tabular}{|c|c|c|c|c|c|c|c|}
\hline Sample & $R^{\dagger}$ & $f_{o c c}$ & $\beta\left(^{\circ}\right)$ & Shell & $\mathrm{CN}$ & $R_{\mathrm{Mn}-\mathrm{O} / \mathrm{Mn}}$ & $\sigma^{2}$ \\
\hline & & & & $\begin{array}{l}\mathrm{Mn}-\mathrm{Mn}_{2}{ }^{*} \\
\mathrm{Mn}-\mathrm{Mn}_{2} \\
\mathrm{Mn}-\mathrm{Mn}_{3} \\
\mathrm{Mn}-\mathrm{Mn}_{3} \\
\mathrm{MnII}-\mathrm{O}\end{array}$ & $\begin{array}{l}6 \\
0 \\
2 \\
4 \\
6\end{array}$ & $\begin{array}{l}4.94(7) \\
- \\
5.65 \\
5.74 \\
2.26(3)\end{array}$ & $\begin{array}{l}0.008 \\
- \\
0.01 \\
0.005\end{array}$ \\
\hline $\begin{array}{l}\mathrm{G} \\
\mathrm{R} 2 \mathrm{~B} 2 \\
\text { grain } 1 \mathrm{pt} . \mathrm{E} \\
k=2.6-11 \AA^{-1}\end{array}$ & 0.0219 & $.54(.10)$ & $16(5)$ & $\begin{array}{l}\mathrm{Mn}-\mathrm{O} \\
\mathrm{Mn}-\mathrm{O} \\
\mathrm{Mn}-\mathrm{Mn}_{1} \\
\mathrm{Mn}-\mathrm{Mn}_{1} \\
\mathrm{Mncor} \\
\mathrm{Mn}-\mathrm{Mn}_{2} \\
\mathrm{Mn}-\mathrm{Mn}_{2} \\
\mathrm{Mn}-\mathrm{Mn}_{3} \\
\mathrm{Mn}-\mathrm{Mn}_{3} \\
\mathrm{MnII}-\mathrm{O}\end{array}$ & $\begin{array}{l}4 \\
2 \\
2 \\
4 \\
.8(4) \\
4 \\
2 \\
2 \\
4 \\
6\end{array}$ & $\begin{array}{l}1.87(1) \\
2.02(2) \\
2.81(2) \\
2.90(2) \\
3.50(3) \\
5.05(6) \\
5.27(.11) \\
5.57 \\
5.74 \\
2.26(2)\end{array}$ & $\begin{array}{l}0.004(1) \\
0.004 \\
0.005(1) \\
0.005 \\
0.005 \\
0.008 \\
0.01 \\
0.004\end{array}$ \\
\hline $\begin{array}{l}\mathrm{H} \\
\mathrm{R} 2 \mathrm{~B} 2 \\
\text { grain } 3 \text { pt. B } \\
k=2.6-12 \AA^{-1}\end{array}$ & 0.0187 & $.67(8)$ & $9(9)$ & $\begin{array}{l}\mathrm{Mn}-\mathrm{O} \\
\mathrm{Mn}-\mathrm{O} \\
\mathrm{Mn}-\mathrm{Mn}_{1} \\
\mathrm{Mn}-\mathrm{Mn}_{1} \\
\mathrm{Mncor}^{*} \\
\mathrm{Mn}-\mathrm{Mn}_{2} \\
\mathrm{Mn}-\mathrm{Mn}_{2} \\
\mathrm{Mn}-\mathrm{Mn}_{3} \\
\mathrm{Mn}-\mathrm{Mn}_{3} \\
\mathrm{MnII}-\mathrm{O}\end{array}$ & $\begin{array}{l}4 \\
2 \\
2 \\
4 \\
1.3(4) \\
4 \\
2 \\
2 \\
4 \\
6\end{array}$ & $\begin{array}{l}1.88(1) \\
1.97(6) \\
2.84(3) \\
2.88(4) \\
3.54(2) \\
4.91(3) \\
5.19(8) \\
5.66 \\
5.75 \\
2.25(2)\end{array}$ & $\begin{array}{l}0.004(2) \\
0.004 \\
0.006(2) \\
0.006 \\
0.006 \\
0.008 \\
0.01 \\
0.004\end{array}$ \\
\hline $\begin{array}{l}\text { I } \\
\text { R2B2 } \\
\text { grain } 3 \text { pt. A } \\
k=3-11.5 \AA^{-1}\end{array}$ & 0.042 & $.62(.10)$ & $4(6.7)$ & $\begin{array}{l}\mathrm{Mn}-\mathrm{O} \\
\mathrm{Mn}-\mathrm{O} \\
\mathrm{Mn}-\mathrm{Mn}_{1} \\
\mathrm{Mn}-\mathrm{Mn}_{1} \\
\text { Mncor } \\
\mathrm{Mn}-\mathrm{Mn}_{2} \\
\mathrm{Mn}-\mathrm{Mn}_{2} \\
\mathrm{Mn}-\mathrm{Mn}_{3} \\
\mathrm{Mn}-\mathrm{Mn}{ }_{3} \\
\mathrm{MnII}-\mathrm{O}\end{array}$ & $\begin{array}{l}6 \\
0 \\
6 \\
0 \\
0.9(5) \\
6 \\
0 \\
6 \\
0 \\
6\end{array}$ & $\begin{array}{l}1.890(8) \\
- \\
2.85(1) \\
- \\
3.43(4) \\
4.83(3) \\
- \\
5.69 \\
- \\
2.23(4)\end{array}$ & $\begin{array}{l}0.0058(6) \\
- \\
0.005(1) \\
- \\
0.0058 \\
0.008 \\
- \\
0.01 \\
- \\
0.0058\end{array}$ \\
\hline $\begin{array}{l}\mathrm{J} \\
\mathrm{R} 2 \mathrm{~B} 2 \\
\text { grain } 4 \\
k=3-11.5 \AA^{-1}\end{array}$ & 0.0030 & $.61(8)$ & $7(5)$ & $\begin{array}{l}\mathrm{Mn}-\mathrm{O} \\
\mathrm{Mn}-\mathrm{O} \\
\mathrm{Mn}-\mathrm{Mn}_{1} \\
\mathrm{Mn}-\mathrm{Mn}_{1} \\
\mathrm{Mncor} \\
\mathrm{Mn}-\mathrm{Mn}_{2} \\
\mathrm{Mn}-\mathrm{Mn}_{2} \\
\mathrm{Mn}-\mathrm{Mn}_{3} \\
\mathrm{Mn}-\mathrm{Mn}_{3} \\
\mathrm{MnII}-\mathrm{O}\end{array}$ & $\begin{array}{l}6 \\
0 \\
6 \\
0 \\
0.9(5) \\
6 \\
0 \\
6 \\
0 \\
6\end{array}$ & $\begin{array}{l}1.907(7) \\
- \\
2.86(1) \\
- \\
3.48(3) \\
4.96(2) \\
- \\
5.72 \\
- \\
2.23(4)\end{array}$ & $\begin{array}{l}0.0048(5) \\
- \\
0.006(1) \\
- \\
0.0048 \\
0.008 \\
- \\
0.01 \\
- \\
0.0048\end{array}$ \\
\hline $\begin{array}{l}\text { Hexagonal } \\
\text { Birnessite } \\
k=2.6-11.5 \AA^{-1}\end{array}$ & 0.0191 & $.83(8)$ & $2(4)$ & $\begin{array}{l}\mathrm{Mn}-\mathrm{O} \\
\mathrm{Mn}-\mathrm{O} \\
\mathrm{Mn}-\mathrm{Mn}_{1} \\
\mathrm{Mn}-\mathrm{Mn}_{1} \\
\mathrm{Mncor} \\
\mathrm{Mn}-\mathrm{Mn}_{2} \\
\mathrm{Mn}-\mathrm{Mn}_{2} \\
\mathrm{Mn}-\mathrm{Mn}_{3} \\
\mathrm{Mn}-\mathrm{Mn}{ }_{3} \\
\mathrm{MnII}-\mathrm{O}\end{array}$ & $\begin{array}{l}6 \\
0 \\
6 \\
0 \\
0.8(4) \\
6 \\
0 \\
6 \\
0 \\
-\end{array}$ & $\begin{array}{l}1.894(5) \\
- \\
2.868(6) \\
- \\
3.48(3) \\
4.93(5) \\
- \\
5.74 \\
-\end{array}$ & $\begin{array}{l}0.0056(4) \\
- \\
0.0048(8) \\
- \\
0.0048 \\
0.014(6) \\
- \\
0.01 \\
- \\
-\end{array}$ \\
\hline $\begin{array}{l}\text { Triclinic birnessite } \\
k=2.6-12.0 \AA^{-1}\end{array}$ & 0.016 & $1.0(.12)$ & $8.8(4)$ & $\begin{array}{l}\mathrm{Mn}-\mathrm{O} \\
\mathrm{Mn}-\mathrm{O}\end{array}$ & $\begin{array}{l}4 \\
2\end{array}$ & $\begin{array}{l}1.87(2) \\
1.92(3)\end{array}$ & $\begin{array}{l}0.007(2) \\
0.0005(9)\end{array}$ \\
\hline
\end{tabular}


Table 3 (continued)

\begin{tabular}{|c|c|c|c|c|c|c|c|}
\hline Sample & $R^{\dagger}$ & $f_{o c c}$ & $\beta\left(^{\circ}\right)$ & Shell & $\mathrm{CN}$ & $R_{\mathrm{Mn}-\mathrm{O} / \mathrm{Mn}}$ & $\sigma^{2}$ \\
\hline & & & & $\mathrm{Mn}-\mathrm{Mn}_{1}{ }^{*}$ & 6 & $2.890(8)$ & 0.007 (1) \\
\hline & & & & $\mathrm{Mn}-\mathrm{Mn}_{1}$ & 0 & & - \\
\hline & & & & Mncor $^{\star}$ & $0.3(4)$ & $3.44(10)$ & 0.007 \\
\hline & & & & $\mathrm{Mn}-\mathrm{Mn}_{2}$ & 6 & $5.00(3)$ & 0.008 \\
\hline & & & & $\mathrm{Mn}-\mathrm{Mn}_{2}$ & 0 & $5.21(5)$ & 0.008 \\
\hline & & & & $\mathrm{Mn}-\mathrm{Mn}_{3}$ & 6 & 5.76 & 0.01 \\
\hline & & & & $\mathrm{Mn}-\mathrm{Mn}_{3}$ & 0 & - & - \\
\hline & & & & MnII-O & 6 & 2.29 & 0.007 \\
\hline
\end{tabular}

itly from the floated parameters for the $\mathrm{Mn}_{1}$ shell as part of the fitting process. This overall approach has the advantage of reducing the total number of varied parameters while increasing fitting constraints on all variables.

The interlayer Na shell and O shells at 3.5 and $4.6 \AA$ of the full Webb model were found to be weakly constrained by the limited data range of the present paper and therefore were not implemented here. These shells interfere with the stronger $\mathrm{Mn}_{1}$ and $\mathrm{Mn}_{2}$ shells, attenuating the amplitude of the latter and thus of the fit-derived value of $f_{\text {occ }}$. Omission of the $3.5-\AA \mathrm{Na}$ and $4.6-\AA \mathrm{O}$ shells in the present study was found to reduce the fit-derived values of $f_{o c c}$ in hexagonal birnessite and triclinic birnessite to an average of 0.85 of the values obtained using the full Webb model (Webb et al., 2005b). To compensate for this deficit and facilitate comparison of the current results to previous EXAFS and XRD studies, the obtained $f_{\text {occ }}$ values listed in Table 3 have been scaled up by a factor of $0.85^{-1}$. In addition, a single $\beta$ axis was used in the present study to capture the average out-of-plane rumpling, as opposed to two axes of the full model.

Fits to the Pinal Creek EXAFS using parameters in Table 3 are shown in Fig. 8. All spectra were well described by the model. We discuss here splitting in the $\mathrm{Mn}-\mathrm{O}$ and $\mathrm{Mn}-$ Mn shells, $\beta$, and $f_{\text {occ }}$ parameters, comparing the bulk samples to individual coatings for each.

3.3.2.1. $M n-O$ shell. The bulk coatings (samples A-D) exhibit split $\mathrm{Mn}-\mathrm{O}$ shells, although the splitting is relatively modest, averaging $0.07 \AA$. The bulk stream-incubated quartz coatings (site SIQ) agreed closely with values obtained from the natural sediments (R2B and Z9A). Splitting of the $\mathrm{Mn}-\mathrm{O}$ shell suggests that $\mathrm{J}-\mathrm{T}$ distorted $\mathrm{Mn}$ (III) is present in the oxides (Manceau et al., 2002; Webb et al., $2005 b$ ). Individual $\mu$-EXAFS points from the oxide coatings generally exhibited a larger range $\mathrm{Mn}-\mathrm{O}$ shell splittings than the bulk coatings, from 0 to $0.15 \AA$, suggesting a greater amount of $\mathrm{Mn}$ (III) than in the bulk coatings. Heterogeneity is evident between grains as well as within contiguous coatings. For example, samples $H$ and $I$, which lie at different azimuthal positions (direction parallel to grain surface) on the same contiguous coating but exhibit contrasting $\mathrm{Mn}-\mathrm{O}$ splitting values.

3.3.2.2. $M n-M n$ shell. Bulk coatings exhibit either unsplit or modestly split $\mathrm{Mn}_{1}$ and $\mathrm{Mn}_{2}$ shells, 0.04 and $0.12 \AA$, respectively (splitting of the $\mathrm{Mn}_{3}$ shell is calculated explicitly from that of $\mathrm{Mn}_{1}$, so is not listed here). The $\mu$-EXAFS points ex- hibit a larger range of $\mathrm{Mn}$ shell splittings, e.g., from $\Delta \mathrm{Mn}_{1}=0$ to $\Delta \mathrm{Mn}_{1}=0.09 \AA$.

3.3.2.3. Out-of-plane bending parameter, $\beta . \quad \beta$ values from the bulk samples are not significantly different from zero. In contrast, $\beta$ values from R2B2 grain 1, pts. $\mathrm{E}$ and $\mathrm{H}$ (spectra $G$ and $E$ in Table 3), and grain 4 exhibit values of $16^{\circ}$ and $10^{\circ}$, implying significant rumpling of the $\mathrm{Mn}$ oxide layer due to the presence of $\mathbf{J}-\mathrm{T}$ distorted $\mathrm{Mn}(\mathrm{III})$ located in layer Mn(IV) sites (Webb et al., 2005b). Individual locations at different grains (R2B2 grain 1, pt E and grain 3, pt A) exhibit $\beta$ values that differ significantly from one-another, again implying that heterogeneity exists between coatings.

3.3.2.4. Fractional occupancy $f_{\text {occ }}$ parameter. Values of $f_{\text {occ }}$ in the bulk coatings, $0.68-0.73$, were uniformly higher than those at the individual spots (0.54-0.67). It should be noted that sorbed $\mathrm{Mn}(\mathrm{II})$, which is present at up to $27 \%$ of total $\mathrm{Mn}$ in some micro-EXAFS points, uniformly attenuates the intensity of Mn-Mn shells, causing $f_{\text {occ }}$ to appear to decrease. This behavior was quantitatively taken into account by adding a Mn(II) shell to the EXAFS fits, with the proportion of $\mathrm{Mn}(\mathrm{II})$ fixed from the XANES fits. Previously reported values of $f_{o c c}$ for hexagonal layer symmetry bacteriogenic $\mathrm{Mn}$ oxides range from 0.50 to 0.83 (Webb et al., 2005c; Villalobos et al., 2006). $f_{\text {occ }}$ values lower than $\sim .80$ previously have been attributed to diminution of particle size, which generates greater numbers of edge sites, and thus apparently lowers occupancy (Webb et al., 2005b). The contribution of edge sites to $f_{o c c}$ is estimated in Section 4.1.

In our experience, beam-induced reduction of biogenic $\mathrm{Mn}$ oxides results in the immediate production of $\mathrm{Mn}$ (II) without detectable concentrations of Mn(III). Moreover, if $\mathrm{Mn}(\mathrm{III})$ were accumulated as a result of beam reduction, it should be small relative to accumulated $\mathrm{Mn}(\mathrm{II})$, which is itself less than about $6 \%$ of total Mn during the time of the data measurement. Such a small amount of $\mathrm{Mn}$ (III) would not be evident in the EXAFS. It is further difficult to see how beam reduction and subsequent production of $\mathrm{Mn}$ (III) could cause the structural disorder in some of the microEXAFS points to decrease to values below those of the bulk average (e.g., $\mathrm{Mn}-\mathrm{O}$ and $\mathrm{Mn}-\mathrm{Mn}$ shells are unsplit in spectra I and J). For these reasons, sample-to-sample and pointto-point variations in EXAFS fit-derived parameters are attributed to conditions that reflect the original physicochemical sample conditions, and not to artifacts of beam reduction. 


\section{DISCUSSION}

\subsection{Particle size}

The general size characteristics of Pinal Creek biooxides can be inferred from several lines of observation. Thickness: TEM images show that the thinnest sheets approach $3 \mathrm{~nm}$ or less. The absence of basal plane reflections from some individual micro-locations (Fig. 2) implies that some Mn oxides were unstacked. Application of the Scherrer equation (Cullity, 1978) to the basal plane XRD peaks in the bulk samples provides an average thickness estimate of $11.6 \pm 0.5 \mathrm{~nm}$ ( $c f$., Electronic appendix). Lateral dimension: TEM images show sheets of diameter 50-500 nm. Particles smaller than ca $50 \mathrm{~nm}$ are difficult to count in the images because of overlap by other sheets. An additional technique was therefore required to more fully assess lateral particle dimensions. Because the illuminated sample volume is well defined and small $\left(1200 \mu \mathrm{m}^{3}\right)$, information regarding average particle size is contained in the root-mean-square intensity variation around the Scherrer rings, i.e., large particles will produce more granular rings than small particles. Quantitative modeling of the $2.48-\AA$ diffraction Scherrer ring (cf., Electronic appendix) provides an average particle volume estimate of $1.09 \pm 0.29 \times 10^{-5} \mu^{3}$. Assuming that the particles are cylindrical plates of thickness $11.6 \mathrm{~nm}$, it can be deduced that the average sheet diameter is $c a 35 \pm 13 \mathrm{~nm}$. Uncertainty quoted here does not account for systematic errors, for example arising from the Scherrer-estimated average particle thickness. The derived particle size should therefore be taken as a general guide. The Scherrer equation was not applied to the 2.48 or $1.44 \AA$ reflections to obtain lateral sheet dimensions (which arise from in-plane scattering and thus in principal contain information on layer diameter) because these peaks may be asymmetrically broadened turbostratic disorder. Moreover, warping of the Mn oxides sheets may in principle reduce the coherent scattering domain size (and hence the Scherrer diameter) to values smaller than the true particle diameter.

$f_{\text {occ }}$ values account for amplitude loss from both particle edge effects and layer site vacancies (Webb et al., 2005b). Edge sites lack their full complement of $\mathrm{Mn}$ neighbors and thus can cause the apparent number of $\mathrm{Mn}$ site vacancies to increase and $f_{\text {occ }}$ to decrease. This effect is most dramatic for sheet diameters $<10 \mathrm{~nm}$ (Webb et al., 2005b). However, even at diameters $>10 \mathrm{~nm}$ there remains a significant impact of particle size on the fit-derived $f_{o c c}$ value. Particles with a true occupancy of 0.85 and diameters of $35 \mathrm{~nm}$ will have an apparent $f_{\text {occ }}$ value of 0.69 (Webb et al., 2005b), which is in the range of fit-derived values observed for the Pinal Creek coatings. The true occupancy factor, removing edge effects for the Pinal Creek biooxides, is thus consistent with a value of $\sim 0.85$, i.e., suggesting that layer site vacancies are present in the Pinal Creek biooxides. This conclusion is in agreement with studies of pure culture biooxides (Webb et al., 2005b; Villalobos et al., 2006).

\subsection{Structure of Pinal Creek biogenic Mn oxides}

XRD and EXAFS results indicate that the hydrated Pinal Creek Mn coatings from all four sites are nanoparticulate layered Mn oxides having $~ 10$ - $\AA$ layer spacings when hydrated (collapsing to $\sim 7 \AA$ upon air drying). The breadth and weakness of the $(001)$ reflections suggest that the $\mathrm{Mn}$ oxide particles comprising the coatings either have a great deal of basal plane spacing disorder or have only a few basal plane layer repeats. The XRD patterns further suggest that the oxides have dominantly hexagonal or pseudo-hexagonal (i.e., distortion of the unit cell occurs to a minimal extent and approximates hexagonal) layer symmetry and that the oxides exhibit turbostratic stacking disorder. The bulk oxide coatings contain layer $\mathrm{Mn}$ (III), as inferred from $\mathrm{J}-\mathrm{T}$ splitting of the $\mathrm{Mn}-\mathrm{O}$ shell and out-of-plane rumpling of the layers, as well as Mn(IV) site vacancies. TEM results are generally consistent with these conclusions. Beyond these similarities, however, there are significant differences between the abraded bulk coatings and individual locations within grain coatings, which are summarized as follows.

\subsubsection{Bulk data}

The bulk coatings contain small amounts of kaolinite not generally observed at individual locations within coatings. $\mathrm{Mn}(\mathrm{II})$ comprises on average $8.2 \%$ of total $\mathrm{Mn}$ in the bulk abraded coatings, likely adsorbed to Mn oxides at edge sites and above $\mathrm{Mn}(\mathrm{IV})$ vacancies as well as to clays. Fits to the EXAFS data suggest that the out-of-plane bending of the oxide layers is not significantly different from planarity over the local structure length scale, i.e., up to about $6 \AA$, consistent with the general structural model for hexagonal birnessite.

\subsubsection{Micron-scale locations within individual coatings}

Individual locations within coatings uniformly contain more $\mathrm{Mn}$ (II) ( $c$ a $20 \%$ of total $\mathrm{Mn}$ ) and lower $f_{\text {occ }}$ values than observed in the bulk abraded faction, the latter finding suggesting smaller particle size and/or more abundant layer vacancies. If the out-of-plane bending angles from individual grain coating locations are averaged, then the obtained result $\left(\beta_{\text {ave }}=9^{\circ}\right)$ is found to be larger than in the abraded bulk coatings $\left(\beta_{\text {ave }}=2^{\circ}\right)$. A similar trend was observed for $\mathrm{Mn}$ O shell splitting parameters ( $c f$., Table 3 ). These observations suggest a somewhat higher average $\mathrm{Mn}$ (III) content within the coatings as compared to the bulk abraded coatings. As a group, individual coating locations exhibit apparently greater variation in $\mathrm{Mn}$ (III) content than the bulk coatings, as inferred from greater variation EXAFS-derived out-ofplane bending angles and splitting of $\mathrm{Mn}-\mathrm{O}$ shells. These results suggest that chemical conditions varied between coatings, and possibly within individual coatings.

\subsection{Stability of Pinal Creek biogenic Mn oxides: constraints on biological oxidation mechanisms}

In general, the stability of $\mathrm{Mn}(\mathrm{III})$-bearing phases such as $\mathrm{MnOOH}$ and $\mathrm{Mn}_{3} \mathrm{O}_{4}$ increases relative to that of $\mathrm{Mn}(\mathrm{IV})$-bearing phases such as $\mathrm{MnO}_{2}$ as $\mathrm{pH}$ and $\mathrm{Mn}(\mathrm{II})$ 
concentration increase, as dictated by the $\mathrm{MnOOH} / \mathrm{MnO}_{2}$ transformation reaction (Mandernack et al., 1995):

$2 \mathrm{H}^{+}+2 \mathrm{MnOOH}=\mathrm{MnO}_{2}+\mathrm{Mn}^{2+}+2 \mathrm{H}_{2} \mathrm{O}$

The chemical conditions of Pinal Creek water at the time of sampling were $\mathrm{pH}$ 6.40-7.0 (Z9A and R2B sites) and 6.46.8 at SIQ. [Mn(II)] values were as high as $820 \mu \mathrm{M}$ (R2B and Z9A samples, $c f$., Table EA-1) and as low as $4.2 \mu \mathrm{M}$ (SIQ samples). The R2B and Z9A [Mn(II)] values were far above the predicted $1 \mu \mathrm{M} \mathrm{Mn}(\mathrm{II})$ concentration that marks the $\gamma-\mathrm{MnOOH} / \mathrm{MnO}_{2}$ boundary at $\mathrm{pH} 6.75$ (assuming equilibrium with atmospheric $\mathrm{O}_{2}$ ). Thus, $\gamma-\mathrm{MnOOH}$ (not observed) is predicted to be more stable than the observed biogenic birnessites for all samples. We conclude that the microbially mediated Mn(II) oxidation/precipitation mechanisms bypassed the formation of $\mathrm{Mn}$ (III) solid phases. This observation is consistent with a $\mathrm{Mn}(\mathrm{II})$ oxidation mechanisms in which $\mathrm{Mn}(\mathrm{IV})$ is enzymatically produced and released to solution, followed by immediate polymerization to form $\mathrm{MnO}_{2}$ (Bargar et al., 2005; Webb et al., 2005a). It has also been proposed that $\mathrm{Mn}(\mathrm{III})$ produced enzymatically or via excitation of photoactive ligand-Mn(II) complexes may disproportionate to $\mathrm{Mn}(\mathrm{II})$ and $\mathrm{Mn}(\mathrm{IV})$, the latter polymerizing to form $\mathrm{Mn}(\mathrm{IV})$ (Hansel and Francis, 2006). Given the relative stability of $\gamma$ $\mathrm{MnOOH}$ in Pinal Creek water, the importance of this latter mechanism would require either enzymatic mediation of the disproportionation step, or relatively slow precipitation kinetics of $\mathrm{Mn}(\mathrm{III})$-bearing phases. In spite of the presence of an apparent thermodynamic driving force to transform into more stable $\mathrm{Mn}$ (III)-oxides/oxyhydroxides or pyrolusite (Best et al., 1999), the biogenic Mn oxides were stable over a time scale of at least 5 months.

\subsection{Evidence in support of biofilm formation environment for Mn oxide coatings}

It is anticipated that hyporheic zone Mn oxides may have formed in microbial biofilms. The lack of particle orientation at the scale of the micro-focused X-ray beam $\left(40 \mu \mathrm{m}^{2}\right)$ is generally consistent with association of $\mathrm{Mn}$ oxides (at least initially) with microbial cells. If Mn oxide nano-sheets were sufficiently abundant to coat the surfaces of $\sim 1-\mu$ m-diameter cells, they would exhibit no net alignment (untextured) when observed with the 40$\mu \mathrm{m}^{2} \mathrm{X}$-ray beam. This would be true even it the nanosheets were each rigorously aligned tangential to the cell surfaces because the oblate spheroid shape of the cells would allow essentially all possible particle orientations to be sampled by the X-ray beam. In contrast, if the Mn oxides were aligned relative to surfaces of the underlying mineral grains, which have diameters $>100 \mu \mathrm{m}$, then the diffracted intensity would have been textured, i.e., concentrated into Scherrer arcs or spots. Other mechanisms that are, in principal, capable of producing untextured $\mathrm{Mn}$ oxide nano-sheets at the scale of $40 \mu \mathrm{m}^{2}$ include unoriented growth or entrapment of $\mathrm{Mn}$ oxide particles in exopolysaccharide (EPS) biofilm. Indeed, the semi-contiguous thin geometry of the coatings (e.g., Figs. 3 and 4) evokes the presence of an enveloping film.
$\mathrm{O}_{2}$ levels can vary sharply in biofilms (Costerton et al., 1995). DeBeer et al. (1994) showed that the $\mathrm{O}_{2}$ concentration within a $40-\mu \mathrm{m}$-diameter biofilm microcolony decreased from ambient levels at the periphery of the microcolony to anoxia at the colony center. In contrast, water channels within the biofilm generally exhibited ambient and sub-ambient $\mathrm{O}_{2}$ concentrations. If such conditions were present during $\mathrm{Mn}$ oxide formation, then spatial variations in $\mathrm{Mn}$ (II) concentrations within and between individual biofilms could have occurred on the scale of a few microns. This model provides an explanation for the observed variation in $\mathrm{Mn}$ oxide structural parameters $\beta$, $\Delta \mathrm{Mn}-\mathrm{O}$, and the inferred $\mathrm{Mn}(\mathrm{III})$ content between abraded bulk grain coatings and within individual coatings.

Grain coatings thinner than $5-10 \mu \mathrm{m}$, i.e., the dominant fraction in the bulk samples, would not have been subjected to strongly attenuated $\mathrm{O}_{2}$ concentrations, and hence would be predicted to have lower $\mathrm{Mn}(\mathrm{II})$ concentrations than the thick $(35 \mu \mathrm{m})$ coatings probed by $\mu$-EXAFS. A biofilm formation model thus provides an explanation for the substantially higher $\mathrm{Mn}(\mathrm{II})$ concentrations observed in the individual grain coatings as compared to the bulk.

\subsection{Comparison to previous studies at Pinal Creek}

We do not observe evidence for tunnel-structure Mn oxides, which contrasts to studies of cemented surface stream crusts collected at Inspiration Dam ( $2.5 \mathrm{~km}$ downgradient from the collection locations in the present paper) (Bilinski et al., 2002). The cemented crust samples are likely to have experienced drying/wetting cycles and to be older than the hyporheic zone coatings examined in the present study, which were still actively forming at the time of collection (Fuller and Harvey, 2000). We therefore conclude that aging and wet/dry cycling may favor conversion of hydrated Ca-birnessites into tunnel-structured oxides. Best et al. (1999) reported the presence of Ca-bearing birnessites in uncemented sediments also collected at the R2B site in May 1997. Bilinski et al. (2002), and Lind and Hem (1993) also reported the presence of Ca-bearing birnessites (rancieite/takanelite) in cemented crusts collected near gaging station 09498400 (at Inspiration Dam) and at Setka Ranch. In all cases, these assignments were based on the presence of a basal plane reflection at $c a 7.3-7.54 \AA$, which compares well to the $\sim 7.4 \AA$ position of the $\left(\begin{array}{lll}0 & 0 & 1\end{array}\right)$ reflection observed in the desiccated samples of the present study. These observations are consistent with our conclusion that $\mathrm{Ca}^{2+}$ is preferentially incorporated as an interlayer cation in the hyporheic zone layered Mn oxides.

Hem and Lind (1983) and Lind and Hem (1996, 1993) proposed an abiotic $\mathrm{Mn}(\mathrm{II})$ oxidation model in which sorbed $\mathrm{Mn}(\mathrm{II})$ is oxidized to form hausmannite $\left(\mathrm{Mn}_{3} \mathrm{O}_{4}\right)$, which subsequently disproportionates to yield $\mathrm{Mn}(\mathrm{IV})$ oxides and $\mathrm{Mn}^{2+}$. This model is thermodynamically plausible at Pinal Creek because hausmannite, which is less stable than the $\mathrm{MnOOH}$ minerals discussed in Section 4.3, can disproportionate into $\mathrm{Mn}(\mathrm{IV})$ oxides under the observed aqueous chemical concentrations (Best et al., 1999). However, neither hausmannite nor Mn(III) oxyhydroxides were observed in this study, nor have been 
reported in Pinal Creek streambed sediments. Moreover, Harvey and Fuller (1998) and Marble et al. (1999) found that $\mathrm{Mn}(\mathrm{II})$ oxidation in biologically active streambed sediment samples was up to 20 -fold faster than in poisoned samples, suggesting that microbial catalysis dominated Mn oxide formation.

\subsection{Comparison to laboratory bacteriogenic Mn oxides}

The Pinal Creek hyporheic zone Mn oxides are generally similar to biogenic Mn oxides produced by pure cultures of Bacillus sp., Pseudomonas putida, and L. discohpora (cf., Section 1). In particular, both laboratory-produced pureculture bacteriogenic Mn oxides and Pinal Creek Mn oxides are nanoparticulate turbostratically disordered or unstacked layered hexagonal Mn oxides containing Mn(IV) site vacancies (Jurgensen et al., 2004; Webb et al., 2005b,c; Villalobos et al., 2006).

Bacteriogenic $\mathrm{Mn}$ oxides produced by Bacillus SG-1 were found to react with $c a 0.1-1 \mathrm{mM}$ aqueous $\mathrm{Mn}^{2+}$, resulting in the incorporation of $\mathrm{Mn}$ (III) into the structure (Bargar et al., 2005). When Mn(II) concentrations exceeded $1 \mathrm{mM}$ (at $\mathrm{pH} 7.8$ ), rapid transformation of the initial bacterial phyllomanganate to feitknechtite $(\beta-\mathrm{MnOOH})$ occurred, controlled by the thermodynamic birnessite/ feitknechtite stability relationship (Bargar et al., 2005). Pinal Creek water at the R2B and Z9A sites $(\mathrm{pH}$ 6.4-7, $\mathrm{Mn}(\mathrm{II})<0.82 \mathrm{mM}$ ) falls within the stability region for birnessite (as compared to feitknechtite), and thus feitknechtite is not predicted to have been produced by such autocatalytic oxidation reactions. However, we can infer from this previous work that the Mn(III) observed in the Pinal Creek biogenic oxides could have been produced from reaction of relatively high and sustained $\mathrm{Mn}$ (II) concentrations (i.e., $>0.1 \mathrm{mM}$ ) with the fresh biogenic layered $\mathrm{Mn}(\mathrm{IV})$ oxides.

The reaction of Bacillus SG-1 Mn biooxides with sea water led to the acquisition of $\mathrm{Ca}^{2+}$ as an interlayer cation, in spite of the fact that $\mathrm{Mg}^{2+}$ is present at 5-fold higher concentration in this medium (Webb et al., $2005 \mathrm{~b}, \mathrm{c}) . \mathrm{Ca}^{2+}$ concentrations in Pinal Creek are $c a$ $10 \mathrm{mM}$, similar to that in sea water. It is therefore not surprising that Pinal Creek biogenic Mn oxides were found to acquire $\mathrm{Ca}^{2+}$ as an interlayer cation. We conclude that an intrinsic affinity of biogenic layered Mn oxides for $\mathrm{Ca}^{2+}$ is responsible for this behavior and that it explains the presence of Ca-bearing birnessites at other locations in Pinal Creek.

Natural marine and soil Mn oxides frequently have been reported to be poorly crystalline and to exhibit layer structures (Post, 1999; Manceau et al., 2005; Bodei et al., 2007). It is likely that such morphologies implicate biogenic origin. This statement is particularly applicable if the local aquatic chemical conditions favor $\mathrm{Mn}$ (III)-bearing solid phases over birnessite. While the morphological evidence is compelling, abiotic mechanisms can not be ruled out, especially considering the ease with which biogenic Mn oxides undergo abiotic transformation to secondary phases (Bargar et al., 2005). More work is required to establish morphology as a biomarker.

\subsection{Implications for natural attenuation of contaminant metals in the hyporheic zone at Pinal Creek}

Fuller and Harvey (2000) proposed that $\mathrm{Zn}$ and Co attenuation in Pinal Creek resulted from uptake by Mn oxides concurrently forming in the hyporheic zone. Up to $20 \%$ of the total Mn load, $45 \%$ of the $\mathrm{Zn}$ load, and $68 \%$ of the Co load was estimated to have been thus naturally attenuated during transport to the basin outflow (Harvey and Fuller, 1998; Fuller and Harvey, 2000). The mechanisms by which metal attenuation occurred and the potential future response of the sequestered contaminants (e.g., following remediation of the upgradient aquifer) are important in this context. The present study helps to explain the sorptive capacity of the Mn oxide coatings. Bacteriogenic and abiotic layered Mn oxides have impressive sorptive capacity for a range of metals, with edge sites and $\mathrm{Mn}(\mathrm{IV})$ vacancy sites being particularly important for contaminant metal binding (Nelson et al., 1999; Lanson et al., 2002b; O'Reilly and Hochella, 2003; Tebo et al., 2004; Villalobos et al., 2005a,b; Toner et al., 2006; Webb et al., 2006). The nanosheet morphology and abundant $\mathrm{Mn}(\mathrm{IV})$ vacancies of the Pinal Creek hyporheic zone Mn oxides should bequeath them with a great abundance of metal-binding sites. Specific structural uptake mechanisms of important Pinal Creek contaminants $\mathrm{Zn}$, Co, and $\mathrm{Ni}$ in the $\mathrm{Mn}$ oxide coatings can be predicted from recent studies of metal sorption in bacteriogenic $\mathrm{Mn}$ oxides and synthetic birnessites. Toner et al. (2006) showed that $\mathrm{Zn}$ (II) sorbed as a tetrahedrally coordinated cation above layer vacancy sites on laboratory bacteriogenic $\mathrm{Mn}$ oxides produced by $P$. putida. $\mathrm{Co}(\mathrm{III})$ and $\mathrm{Ni}(\mathrm{II})$ have been shown to substitute at Mn layer sites in abiotic and bacteriogenic layered $\mathrm{Mn}$ oxides. Ni also has been shown to bond above vacant Mn layer sites as for Zn(II) (Manceau et al., 1997, 2007; Peacock and Sherman, 2007). Also important, the ongoing formation of reactive coatings in the presence of the dissolved metal contaminants provides an efficient mechanism by which metals can be sorbed and structurally incorporated into Mn oxides, as proposed by Fuller and Harvey (2000).

\section{ACKNOWLEDGMENTS}

We thank Apurva Mehta, Brian Valek, and Nobmichi Tamura for their helpful discussions and support regarding microdiffraction measurements and data analysis. We thank A. Condon and M. Conklin for providing samples from sites SIQ and AK-1. Discussions with and field support from Jud Harvey, M. Conklin and P. O'Day and their students were beneficial throughout this study. We also thank D. Kent, Y. Arai, and three anonymous reviewers for their many helpful comments. This work was supported by the Department of Energy, Office of Basic Energy Sciences (SLAC Contract DE-AC03-76SF00515), by NSF-CRAEMS Grant to Bargar (CHE-0089208), and by the US Geological Survey Toxics Substance Hydrology Research Program to Fuller. Portions of this research were carried out at the Stanford Synchrotron Radiation Lightsource a national user facility operated by Stanford University on behalf of the U.S. Department of Energy, Office of Basic Energy Sciences. The SSRL Structural Molecular Biology Program is supported by the Department of Energy, Office of Biological and Environmental Research, and by the National Institutes of Health, National Center for Research Resources, Biomedical Technology 
Program. The operations of the Advanced Light Source at the Lawrence Berkeley National Laboratory are supported by the U.S. Department of Energy, Office of Basic Energy Sciences, under Contract No. DE-AC02-05CH11231. Transmission electron microscopy performed at the University of New Mexico was carried out in the Electron Microbeam Analysis Laboratory, a facility supported by funds from NASA, National Science Foundation through the National Nanoscience Infrastructure Network (NNIN) and the state of New Mexico. Any use of trade, product, or firm names in this publication is for descriptive purposes only and does not imply endorsement by the U.S. Government.

\section{APPENDIX A. SUPPLEMENTARY DATA}

Supplementary data associated with this article can be found, in the online version, at doi:10.1016/ j.gca.2008.10.036.

\section{REFERENCES}

Bargar J. R., Tebo B. M., Bergamann U., Webb S. M., Glaetzel P., Chiu V. Q. and Villalobos M. (2005) Biotic and abiotic products of $\mathrm{Mn}$ (II) oxidation by spores of the marine Bacillus sp. strain SG-1. Am. Miner. 90, 143-154.

Best J. E., Geiger K. E. and O'Day P. A. (1999) Partitioning of trace metals between contaminated stream waters and manganese oxide minerals, Pinal Creek, Arizona. In Water-Resources Investigations Report (United States Geological Survey) 994018A. U.S. Geological Survey Toxic Substances Hydrology Program, 1999, vol. 1, pp. 227-237.

Bilinski H., Giovanoli R., Usui A. and Hanzel D. (2002) Characterization of $\mathrm{Mn}$ oxides in cemented streambed crusts from Pinal Creek, Arizona, U.S.A., and in hot-spring deposits from Yuno-Taki Falls, Hokkaido, Japan. Am. Miner. 87, 580891.

Bodei S., Manceau A., Geoffroy N., Baronnet A. and Buatier M. (2007) Formation of todorokite from vernadite in Ni-rich hemipelagic sediments. Geochim. Cosmochim. Acta 71, 56985716.

Brown J. G. and Eyechaner J. H. (1996) Research of acidic contamination of ground water and surface water, Pinal Creek Basin, Arizona. In Hydrology and Geochemistry of Aquifer and Stream Contamination Related to Acidic Water in Pinal Creek Basin Near Globe. US Geological Survey Water-Supply Paper 2466, Arizona, Chapter A(1-20).

Brown J. G., Glynn P. D. and Bassett R. L. (1999) Geochemistry and reactive transport of metal contaminants in ground water, Pinal Creek Basin, Arizona. In Water-Resources Investigations Report (United States Geological Survey) 99-4018A. U.S. Geological Survey Toxic Substances Hydrology Program, 1999, vol. 1, pp. 141-153.

Brown J. G. and Harvey J. W. (1996) Hydrologic and geochemical factors affecting metal-contaminant transport in Pinal Creek basin near Globe, Arizona. In U.S. Geological Survey Toxic Substances Hydrology Program-Proceedings of the Technical Meeting, September 20-24, 1993 (eds. D. W. Morganwalp and D. A. Aronson). U.S. Geological Survey Water-Resources Investigations Report 94-4015, U.S. Geological Survey, vol. 2, pp. 1035-1042.

Burns R. G. and Burns V. M. (1979) Manganese oxides. In Marine Minerals (ed. R. G. Burns). Mineralogical Society of America, pp. 1-46.

Buseck P. R. (1992) Principles of transmission electron microscopy. Mineral reactions at the atomic scale: transmission electron microscopy. In Reviews in Mineralogy, vol. 27 (ed. P. R. Buseck). Mineralogical Society of America, pp. 1-36.

Choi J., Hulseapple S., Conklin M. H. and Harvey J. W. (1998) Modeling $\mathrm{CO}_{2}$ degassing and $\mathrm{pH}$ in a stream-aquifer system. $J$. Hydrol. 209, 297-310.

Condon A. K. (2003) Investigation of Zinc Uptake Processes by Manganese-Oxide-Coated Sediments from a Mining-Contaminated Stream, Pinal Creek, Arizona. Masters Thesis, University of Arizona.

Costerton J. W., Lewandowski Z., Caldwell D. E., Korber D. R. and Lappin-Scott H. M. (1995) Microbial biofilms. Ann. Rev. Microbiol. 49, 711-745.

Cullity B. D. (1978) Elements of X-ray Diffraction. AddisonWesley, Reading, MA.

DeBeer D., Stoodley P., Roe F. L. and Lewandowski Z. (1994) Effects of biofilm structure on oxygen distribution and mass transport. Biotechnol. Bioeng. 43, 1131-1138.

Eychaner J. H. (1991) The Globe, Arizona, research sitecontaminants related to copper mining in a hydrologically integrated environment. In U.S. Geological Survey Toxic Substances Hydrology Program-Proceedings of the Technical Meeting, Monterey, California, 1991. Water-Resources Investigations Report 91-4034 (eds. G. E. Mallard and D. A. Aronson), U.S. Geological Survey, pp. 439-447.

Fuller C. C. and Harvey J. W. (2000) Reactive uptake of trace metals in the hyporheic zone of a mining-contaminated stream, Pinal Creek, Arizona. Environ. Sci. Technol. 34, 1150-1155.

Hansel C. M. and Francis C. A. (2006) Coupled photochemical and enzymatic $\mathrm{Mn}(\mathrm{II})$ oxidation pathways of a planktonic Roseobacter-like bacterium. Appl. Environ. Microbiol. 72, 3543 3549.

Harvey J. W. and Fuller C. C. (1998) Effect of enhanced manganese oxidation in the hyporheic zone on basin-scale geochemical mass balance. Water Resour. Res. 34, 623-636.

Hem J. D. and Lind C. J. (1983) Nonequilibrium models for predicting forms of precipitated manganese oxides. Geochim. Cosmochim. Acta 47, 2037-2046.

Huang P. M. (1991) Kinetics of redox reactions on manganese oxides and its impact on environmental quality. In Rates of Soil Chemical Processes (eds. D. L. Sparks and D. L. Suarez). Soil Science Society of America, Inc., pp. 191-230.

Jenne E. A. (1967) Controls on $\mathrm{Mn}, \mathrm{Fe}, \mathrm{Co}, \mathrm{Ni}, \mathrm{Cu}$ and $\mathrm{Zn}$ concentrations in soils and water: the significant role of hydrous $\mathrm{Mn}$ and $\mathrm{Fe}$ oxides. In Trace Inorganics in Water. American Chemical Society, Washington, DC, pp. 337-387.

Jurgensen A., Widmeyer J., Gordon R., Bendell-Young L., Moore M. and Crozier E. (2004) The structure of the manganese oxide on the sheath of the bacterium Leptothrix discophora: an EXAFS study. Am. Miner. 89, 1110-1118.

Kay J. T., Conklin M. H., Fuller C. C. and O'Day P. A. (2001) Processes of nickel and cobalt uptake by a manganese oxide forming sediment in Pinal Creek, Globe Mining District, Arizona. Environ. Sci. Technol. 35, 4719-4728.

Lanson B., Drits V. A., Feng Q. and Manceau A. (2002a) Structure of synthetic Na-birnessite: evidence for a triclinic one-layer unit cell. Am. Miner. 87(11-12), 1662-1671.

Lanson B., Drits V. A., Gaillot A. C., Silvester E., Plancon A. and Manceau A. (2002b) Structure of heavy-metal sorbed birnessite. Part 1: Results from X-ray diffraction. Am. Miner. 87(11-12), 1631-1645.

Lanson B., Drits V. A., Silvester E. and Manceau A. (2000) Structure of $\mathrm{H}$-exchanged hexagonal birnessite and its mechanism of formation from Na-rich monoclinic buserite at low $\mathrm{pH}$. Am. Miner. 85(5-6), 826-838.

Lind C. J. and Hem J. D. (1993) Manganese minerals and associated fine particulates in the streambed of Pinal Creek, 
Arizona, USA: a mining-related acid drainage problem. Appl. Geochem. 8, 67-80.

Lind C. J. and Hem J. D. (1996) Manganese and iron oxide deposits and trace-metal associations in stream sediments, Pinal Creek Basin, Arizona. In Hydrology and Geochemistry of Aquifer and Stream Contamination Related to Acidic Water in Pinal Creek Basin Near Globe, Arizona. US Geological Survey Water-Supply Paper 2466, Chapter E, pp. 81-103.

Manceau A., Drits V. A., Silvester E., Bartoli C. and Lanson B. (1997) Structural mechanism of $\mathrm{Co}^{2+}$ oxidation by the phyllomanganate buserite. Am. Miner. 82, 1150-1175.

Manceau A., Lanson M. and Geoffroy N. (2007) Natural speciation of $\mathrm{Ni}, \mathrm{Zn}, \mathrm{Ba}$, and $\mathrm{As}$ in ferromanganese coatings on quartz using X-ray fluorescence, absorption, and diffraction. Geochim. Cosmochim. Acta 71(1), 95-128.

Manceau A., Marcus M. A. and Tamura N. (2002) Quantitative speciation of heavy metals in soils and sediments by synchrotron Xray techniques. In Applications of Synchrotron Radiation in LowTemperature Geochemistry and Environmental Science. Reviews in Mineralogy and Geochemistry, vol. 49 (eds. P. Fenter and N. C. Sturchio). Mineralogical Society of America, pp. 341-428.

Manceau A., Tommaseo C., Rihs S., Geoffroy N., Chateigner D., Schlegel M., Tisserand D., Marcus M. A., Tamura N. and Chen Z. S. (2005) Natural speciation of $\mathrm{Mn}, \mathrm{Ni}$, and $\mathrm{Zn}$ at the micrometer scale in a clayey paddy soil using X-ray fluorescence, absorption, and diffraction. Geochim. Cosmochim. Acta 69, 4007-4034

Mandernack K. W., Post J. and Tebo B. M. (1995) Manganese mineral formation by bacterial spores of the marine Bacillus strain SG-1: evidence for the direct oxidation of $\mathrm{Mn}$ (II) to $\mathrm{Mn}(\mathrm{IV})$. Geochim. Cosmochim. Acta 59, 4393-4408.

Manies K. L., Harden J. W., Silva S. R., Briggs P. H. and Schmid B. M. (2004) Soil data from Picea mariana stands near Delta Junction, AKJ of different ages and soil drainage type. U.S. Geological Survey Open File Report 2004-1271, U.S. Geological Survey.

Marble J. C., Corley T. L., Conklin M. H. and Fuller C. C. (1999) Environmental factors affecting oxidation of manganese in Pinal Creek, Arizona. In Water-Resour. Invest. Rep. 99-4018A (eds. D. W. Morganwalp and H. T. Buxton), US Geological Survey, pp. 173-183.

Marcus M., MacDowell A. A., Celestre R., Manceau A., Miller T., Padmore H. A. and Sublett R. E. (2004) Beamline 10.3.2 at ALS: a hard X-ray microprobe for environmental and materials sciences. J. Synchrotron Radiat. 11, 239-247.

Morgan J. J. (2005) Kinetics of reaction between $\mathrm{O}_{2}$ and $\mathrm{Mn}(\mathrm{II})$ species in aqueous solutions. Geochim. Cosmochim. Acta 69, 35-48.

Murray J. W. (1975) The interaction of metal ions at the manganese dioxide-solution interface. Geochim. Cosmochim. Acta 39, 505-519.

Nelson Y. M., Lion L. W., Ghiorse W. C. and Shuler M. L. (1999) Production of biogenic Mn oxides by Leptothrix discophera SS-1 in a chemical defined growth medium and evaluation of their $\mathrm{Pb}$ adsorption characteristics. Appl. Environ. Technol. 65, 175-180.

Newville M. (2001) IFEFFIT: interactive XAFS analysis and FEFF fitting. J. Synchrotron Radiat. 8, 324-332.

O'Reilly S. E. and Hochella, Jr., M. F. (2003) Lead sorption efficiencies of natural and synthetic $\mathrm{Mn}$ and Fe-oxides. Geochim. Cosmochim. Acta 67, 4471-4487.

Peacock C. L. and Sherman D. M. (2007) Crystal-chemistry of Ni in marine ferromanganese crusts and nodules. Am. Miner. 92, $1087-1092$.

Post J. E. (1999) Manganese oxide minerals: crystal structures and economic and environmental significance. Proc. Natl. Acad. Sci. USA 96, 3447-3454.
Rehr J. J., Zabinsky S. I. and Albers R. C. (1992) High-order multiple-scattering calculations of X-ray absorption fine structure. Phys. Rev. Lett. 69, 3397.

Reynolds, Jr., R. C. (1989) Modern powder diffraction. In Modern powder diffraction, vol. 20 (eds. D. L. Bish and J. E. Post), pp. 145-181. Reviews in Mineralogy. Mineralogical Society of America.

Robbins E. I. and Corley T. L. (2005) Microdynamics and seasonal changes in manganese oxide epiprecipitation in Pinal Creek, Arizona. Hydrobiologia 534, 165-180.

Self P. (1992) High-resolution image simulation and analysis. mineral reactions at the atomic scale: transmission electron microscopy. In Reviews in Mineralogy, vol. 27 (ed. P. R. Buseck). Mineralogical Society of America, pp. 85-112.

Stollenwerk K. G. (1994) Geochemical interactions between constituents in acidic groundwater and alluvium in an aquifer near Globe, Arizona. Appl. Geochem. 9, 353-359.

Tebo B. M., Bargar J. R., Clement B., Dick G., Murray K. J., Parker D., Verity R. and Webb S. (2004) Manganese biooxides: properties and mechanisms of formation. Ann. Rev. Earth Planet. Sci. 32, 287-328.

Thomson E. A., Luoma S. N., Cain D. J. and Johansson C. (1980) The effect of sample storage on the extraction of $\mathrm{Cu}, \mathrm{Zn}, \mathrm{Fe}$, $\mathrm{Mn}$, and organic material from oxidized estuarine sediments. Water Air Soil Pollut. 14, 215-233.

Toner B., Manceau A., Webb S. M. and Sposito G. (2006) Zinc sorption to biogenic hexagonal-birnessite particles within a hydrated bacterial biofilm. Geochim. Cosmochim. Acta 70(1), 27-43.

Villalobos M., Bargar J. R. and Sposito G. (2005a) Mechanisms of $\mathrm{Pb}$ (II) sorption on a biogenic manganese oxide. Environ. Sci. Technol. 39, 569-576.

Villalobos M., Bargar J. R. and Sposito G. (2005b) Trace metal retention on biogenic manganese oxide nanoparticles. Elements 1, 223-226.

Villalobos M., Lanson B., Manceau A., Toner B. and Sposito G. (2006) Structural model for the biogenic Mn oxide produced by Pseudomonas putida. Am. Miner. 91, 489-502.

Villalobos M., Toner B., Bargar J. and Sposito G. (2003) Characterization of the manganese oxide produced by Pseudomonas putida strain MnB1. Geochim. Cosmochim. Acta 67, 2649-2662.

Webb S. M. (2003) SIXPACK: a graphical user interface for XAS analysis using IFEFFIT. Phys. Scripta T115, 1011-1014.

Webb S. M., Bargar J. R., Dick F. J. and Tebo B. M. (2005a) Evidence for the presence of $\mathrm{Mn}(\mathrm{III})$ intermediates in the bacterial oxidation of Mn(II). Proc. Natl. Acad. Sci. USA 102, $5558-5563$.

Webb S. M., Tebo B. M. and Bargar J. R. (2005b) Structural characterization of biogenic manganese oxides produced in sea water by the marine Bacillus sp., strain SG-1. Am. Miner. 90, $1342-1357$.

Webb S. M., Tebo B. M. and Bargar J. R. (2005c) Structural influences of sodium and calcium ions on biogenic manganese oxides produced by the marine Bacillus sp., strain SG-1. Geomicrobiol. J. 22, 181-193.

Webb S. M., Fuller C. C., Tebo B. M. and Bargar J. R. (2006) Determination of uranyl incorporation into biogenic manganese oxides using X-ray absorption spectroscopy and scattering. Environ. Sci. Technol. 40, 771-777. 